\title{
The Nature of Money in a Convertible Currency World
}

\section{CAROLYN SISSOKO*}

\begin{abstract}
In a world where the means of exchange is convertible into the numeraire consumption good at a fixed rate, no one wants to hold money over time - and due to convertibility there is no means by which the Friedman rule can generate deflation. This is the environment we study in this paper in order to demonstrate that there is still a way to reach the first-best: institutionalize the naked shorting of the unit of account, or in other words establish a banking system. To motivate the benefits of a banking system, the environment has real productivity shocks that are constantly changing the optimal level of economic activity, so the optimal quantity of money is inherently stochastic. Efficiency in such an environment requires the capacity to expand the money supply on an "as needed" basis. We show how a debt-based payments system that relies on banks to certify the individual debtors' IOUs addresses the monetary problem. This model explains (i) central bank monetary policy as a means of stabilizing the banking system and (ii) usury laws as means of promoting equilibria that favor non-banks over those that favor banks. Furthermore, by modeling a commercial bank-based monetary system as an efficient solution to a payments problem this paper develops a theoretic framework that may be used to evaluate central bank digital currency proposals.
\end{abstract}

Keywords: Money, Banking, Commercial bills, Financial stability, Usury laws

JEL Classifications: E5, G2

\section{Introduction}

This paper studies the nature of money in an environment where the means of payment is convertible at a fixed rate into the numeraire consumption good. By focusing on this environment we eliminate the possibility that the means of payment changes value over time, and deliberately construct a situation where the price level is disabled as a means of equilibrating the supply of money with the demand for it. To our knowledge no one else has studied such an environment in a Lagos-Wright-type framework. Our goal in this paper is to demonstrate that in this environment the first-best can still be attained - if the means of payment is effectively a naked short of the unit of account.

\footnotetext{
* Many thanks go to Randy Wright who encouraged me to sit down and write this paper and gave me invaluable comments, and to David Andolfatto, Charles Goodhart, Chao Gu, Charles Kahn, Fabrizio Mattesini, Cyril Monnet, Ed Nosal, and Alberto Trejos for very helpful comments. All errors are, of course, my own.

Affiliation: Independent researcher. Author contact: 10747 Flaxton St. Culver City CA 90230 USA. Phone: (310) 7365773. Email: csissoko5@gmail.com

(C) 2021 Carolyn Sissoko . Licensed under the Creative Commons Attribution - Noncommercial 4.0 Licence (http://creativecommons.org/licenses/by-nc/4.0/. Available at http://rofea.org.
} 
A naked short has the effect of creating a "phantom" supply of the shorted object that disappears when the short is closed out. We demonstrate here that banks can create this "phantom" supply of the unit of account in the form of acceptances of private debt. ${ }^{2}$ This type of bank liability is issued when the bank stamps a private commercial bill "accepted," and the bank obligation is put into circulation when the borrower makes purchases. Then, when the borrower pays off the loan, the phantom supply of the unit of account along with the outstanding, but contingent, bank liability that was used to create it is closed out.

Why do we model the means of payment as a naked short of the unit of account? We argue, first, that this is the best way to understand the nature of the banking system in its developmental stages. Second, by modelling the means of payment in this way our model demonstrates the efficiency gains that can be created through the introduction of a banking system. Third, by carefully evaluating the incentive feasibility conditions for our bank money equilibria, we are able to relate the monetary system to banking stability. We find that the implementation of central bank monetary policy via interest rates can be explained by the need to stabilize the banking system. Finally, we also find support for the use of usury laws as a means by which policymakers choose amongst multiple equilibria to favor the interests of non-banks over those of banks.

The monetary system modelled in this paper is based on the $18^{\text {th }}$ century British monetary system as described in Henry Thornton (1802) An enquiry into the nature and effects of the paper credit of Great Britain. Privately issued bills function as a means of payment because they are "accepted" as liabilities by the banks that underwrite the monetary system. While these bills were denominated in a gold-based unit of account, ${ }^{3}$ as a practical matter there was no expectation that they would be settled in gold. Instead, they were used as a means of transferring bank liabilities from one tradesman to another. Thus, bills that are simultaneously private IOUs and bank liabilities are used to make payment. The non-bank debtor pays off her debt by depositing someone else's bank-certified liability into her account. (The $18^{\text {th }}$ century monetary system was the precursor of the checking account system and operates just like a system of overdraft accounts.) The bank's liability on a deposited bill is extinguished when funds are credited to the depositor's account.

In our model productivity is stochastic, and as a result the demand for money is stochastic. We show that the bank-based money described in our model can accommodate this stochastic money demand so that a first best is attained. Thus, our model can be viewed as a model of the

\footnotetext{
${ }^{2}$ While it would be easy to reconfigure the means of payment to be deposits or bank notes, we believe the monetary function of bank liabilities in this paper is sufficiently different from the existing literature that it useful to present it using an unfamiliar instrument.

${ }^{3}$ For the purposes of keeping the exposition simple, assume that we model the monetary system prior to 1797 (when gold convertibility was suspended).
} 


\section{SISSOKO The Nature of Money}

"banking school" view where money is issued on an "as needed" basis at the demand of nonbanks.

We argue that the convertible currency environment forces a reconsideration of the nature of money. Typically the monetary literature views money as "an object that does not enter utility or production functions, and is available in fixed supply" (Kocherlakota 1998). Shifts in the price of money equilibrate the economy in these environments. Historically, however, stabilization of the price of money by tying it to a fixed quantity of gold was a foundation of economic success in the early modern period (van Dillen 1964; Bayoumi \& Eichengreen 1995). Thus, we consider how money functions in an environment where its price is "anchored". We show that a solution is for the means of payment to be a debt instrument that is denominated in the anchored unit of account and is certified by a bank. This solution is based on actual market practice in the early modern period.

This approach allows us to reinterpret general results such as Gu, Mattesini, and Wright (2014) (GMW)'s finding that when credit is easy, money is useless, and when money is essential, credit is irrelevant. While their conclusion is correct given their definitions of money and credit, we argue that this standard definition of money is not the correct definition to apply to an environment with banks. We argue that the means of payment in an environment with banks is a naked short of the unit of account, which would be categorized in GMW's lexicon as "credit".

This paper employs the methods of new monetarism. Our model combines an environment based on Berentsen, Camera, and Waller (2007) with an approach to banking that is more closely related to Gu, Mattesini, Monnet, and Wright (2013) (GMMW) and Cavalcanti and Wallace (1999a,b). Our model of banking is distinguished from GMMW because non-bank borrowing is supported not by collateral, but by an incentive constraint alone, and from Cavalcanti and Wallace because our banks don't issue bank notes, but instead certify privately issued IOUs. We find that for values of the discount rate that accord with empirical evidence, such a payments system can be operated with no risk of default simply by setting borrowing constraints. ${ }^{4}$ We start by finding the full range of incentive feasible equilibria of the model, and then discuss how, when there are multiple equilibria, a policymaker may choose between these equilibria.

In this environment competitive banking is incentive feasible only when enforcement is exogenous. In the case of endogenous enforcement, competition in banking typically drives the returns to banking below what is incentive feasible and the only equilibrium will be autarky. This result is consistent with many other papers that have found that the welfare of non-banks

\footnotetext{
${ }^{4}$ Indeed, we argue elsewhere that the credit based on precisely such constraints constituted the "safe assets" of the monetary system through the developmental years of banking (Sissoko 2016). Treasury bills, the modern financial world's safe assets, were introduced in 1877 and modeled on the private money market instruments of $19^{\text {th }}$ century Britain (Roberts 1995: 155).
} 
is improved when there is a franchise value to banking (Martin and Schreft 2005, Monnet and Sanches 2015, Huang 2017. See also Demsetz et al. 1996).

Thus, the challenge for a policymaker is how to regulate competition in the banking sector so that banking is both incentive compatible - and therefore stable - and also meets the policymaker's goals in terms of serving non-banks. One solution is to treat banking as a natural monopoly, allowing an anti-competitive structure while at the same time imposing a cap on the fees that can be charged by banks. This solution explains usury laws, which by capping interest rates at a level such as $5 \%$, the rate in $18^{\text {th }}$ century Britain, is able to generate both a robust franchise value for the banks that provide payments system credit and at the same time to ensure that a significant fraction of the gains created by the existence of an efficient means of payment accrue to non-banks. An alternate solution is to impose a competitive structure on the banking industry, but also to set a minimum interest rate as a floor below which competition cannot drive the price. We argue that this is the practice of modern central banks and thus that monetary policy should be viewed as playing an important role in preventing competition from destabilizing the banking sector.

Section I introduces the model of a convertible currency. Section II describes the equilibria of the model. Section III presents the equilibria using diagrams. Section IV discusses the means by which policymakers choose between the different equilibria of the bank-based monetary system. Section V concludes.

\section{A Model of Convertible Bills as a Means of Payment}

Time is discrete, indexed by $t=0,1,2, \ldots$, and extends over an infinite horizon. Following Berentsen, Camera, and Waller (2007) (BCW) in each period two perfectly competitive markets open sequentially. There are two consumption goods, $x$, which is perishable and must be consumed during the first market (FM) and $X$, which is perishable and must be consumed during the second market. The second market will be abbreviated $\mathrm{CM}$, because this market plays the same role as the centralized market in the Lagos-Wright (2005) framework upon which BCW is built. Note that the model of banking here is very different from the model of banking in BCW and is closer in spirit to the model of banking in Gu Mattesini Monnet and Wright (2013).

There is no discounting between the FM and the CM. The discount factor from one period to the next is given by $\beta$.

There are two types of agents, non-banks and banks, and there is a continuum of mass one of each type of agent. Non-banks experience a preference shock at the beginning of each period such that with probability $n$ the agent is a "lender" and with probability $1-n$ the agent is a "borrower." (This nomenclature anticipates the roles that the two types will play in the model.) Lenders can only produce in the FM at $\operatorname{cost} c(q)=q^{2} / 2 A$ where $q$ is the amount produced of $\operatorname{good} x$ and $A$ is a production shock. The production shock takes one of two values $A \in\{1, \bar{A}\}$ 


\section{SISSOKO The Nature of Money}

with $\operatorname{Pr}\{A=\bar{A}\}=\sigma$ and $\operatorname{Pr}\{A=1\}=1-\sigma$. In the CM lenders can only consume, deriving utility $U(X)=X$. Borrowers can only consume in the FM, deriving utility $u(x)=x^{\alpha}$ where $\alpha \in(0,1)$. In the CM borrowers produce at $\operatorname{cost} C(Q)=Q$, where $Q$ is the quantity of $\operatorname{good} X$ produced. Banks do not produce and consume only in the $\mathrm{CM}$, deriving utility $U(X)=X$. Both forms of uncertainty, the preference shock and the production shock, are realized at the start of each period. These shocks are publicly observable.

As in $\mathrm{BCW}$, we assume that the goods trades that take place in the FM and the CM are anonymous, that agents cannot identify their trading partners, and that trading histories are private information. A borrower cannot commit to paying a lender in the future, because he will not be able to meet and identify the right lender. Thus, in the absence of some kind of a monetary device, anonymity will force the economy to be autarkic in the FM.

Banks have a technology that makes it possible for them to record the financial history (but not the trading history) of each member of the economy. The account-keeping technology is operated costlessly. Banks also have a public history: if at the close of the period interbank clearing leaves a bank with a negative net worth, then the bank is forced to declare bankruptcy publicly.

\section{Acceptance banking}

Banks offer credit lines to borrowers up to a limit, $\bar{\ell}$, which is endogenous and ensures that repayment of debt is incentive compatible for the borrower. Bank liabilities - and therefore the credit line and any bills that draw down the credit line - are denominated in the CM good. Not only are they denominated in the CM good, but they are anchored to it: they are convertible into the CM good at a fixed rate at any point in time. Thus, if a bill circulates from one period to the next it represents a promise to pay the same quantity of the CM good in whatever period the bill is presented.

A borrower draws down on the credit line by issuing a bill that is instantaneously accepted by the borrower's bank. This has two effects: it converts the bill into an accepted bill that is a liability of the bank similar to a bank note and it draws down the credit line that the bank has extended to the borrower. Commercial bills are modeled here as bearer bills, and are payable to whoever holds them.

Thus, in an acceptance banking system a single commercial bill plays two distinct roles. First, the commercial bill is a loan that draws down the credit line that a bank has extended to the issuer. Second, because an accepted commercial bill is a bank liability, third parties are willing to receive it in payment and it circulates as money. Thus, the physical document that is an accepted commercial bill is simultaneously both a bank loan and a bank note.

The distinguishing characteristic of an accepted bill is that there are two parties who are both fully liable for payment of the bill, the non-bank issuer and the bank-acceptor. The liability to the bank of the issuer of the commercial bill is extinguished when the issuer deposits accepted 
bills equal in value to his debt in his account. A bank's liability on an accepted bill is extinguished when the accepted bill is deposited into a bank account and thus it no longer circulates. The details of how the banks operate a clearing and settlement system are omitted from the model. ${ }^{5}$

Banks also have the technology to circulate their bills in the CM in order to purchase the consumption good. Such a circulation of bills is, however, inherently fraudulent, because in this model there is no way for such bills to be paid and their issue guarantees that the issuing bank will be bankrupt at the end of the period. Since the banks have the technology to profit from such a default, the banks face an endogenous limit on their liabilities, $\bar{b}$. At the end of a period in which a bank fraudulently circulates bills, the bank will be bankrupt and be forced into autarky. This technology is only available to a bank that was active in lending in the FM - a restriction that can be viewed as an aspect of the bank's public history.

In this model banks offer loans that extend from the FM to the $\mathrm{CM}$ of a given period. Observe that even after a loan is paid off by its issuer (by depositing funds into his account to cover the bill), the accepted bill that created the loan may continue to circulate as a bank liability until such time as the holder of the accepted bill chooses to present it to a bank.

After the realization of the uncertainty at the start of the FM, trade in the first market takes place and borrowers issue bills that draw down their bank credit lines. Such loans are denoted by $\ell \in[0, \bar{\ell}]$, and the interest rate, $i \geq 0$, is charged on the loan and payable in the CM along with the principal of the loan. The punishment for a default on a loan is loss of access to bank services in the future. Let $d \in[0, \infty)$ represent physical holdings of accepted bills.

The First-Best Allocation: To find the first best allocation we assume that all agents are treated symmetrically. The problem is the same in each period except for the production shock. We consider the first-best allocation to be the allocation that a social planner would choose in each period if she could allocate consumption after learning the outcome of the production shock.

After the realization of the production shock, but before the realization of the preference shock, in each period a representative agent has the expected utility:

$$
(1-n)\left(x^{\alpha}-Q\right)+n\left(-\frac{q^{2}}{2 A}+X\right)
$$

And optimization will be subject to the FM and CM feasibility constraints:

$$
(1-n) x=n q
$$

\footnotetext{
${ }^{5}$ The focus on symmetric equilibria and banks that are in all respects identical means that this amounts to unnecessary detail here.
} 


\section{SISSOKO The Nature of Money}

$$
(1-n) Q=n X
$$

The first order conditions of this problem indicate that optimal FM consumption is

$$
x^{* *}(A)=\left[\frac{\alpha n A}{(1-n)}\right]^{\frac{1}{2-\alpha}}
$$

optimal FM production is:

$$
q^{* *}(A)=\frac{1-n}{n} x^{* *}(A)
$$

and that all values that satisfy the CM feasibility constraint will be optimal. Thus, the quantities that a social planner who could force agents to produce and consume would choose in each period are given by $x^{* *}(A)$ and the feasibility constraints.

\section{Symmetric Equilibrium}

Following $\mathrm{BCW}$, we limit our attention to stationary symmetric equilibria where each type of agent plays the same pure strategy. We first analyze the choices made by a lender in the second market, then in the first market, and then we analyze the borrower's choices. Only after optimizing choices in each of the markets have been established do we fully specify all of the relevant value functions.

To simplify notation, current period variables will be denoted without a subscript, next period variables with prime mark and previous period variables with the subscript -1 .

The Lender's Problem: Observe that a lender - who does not intend to default - derives only costs and no benefits from borrowing. For this reason, banks will not extend loans to lenders. Then, letting $W^{l}(d)$ represent the value to a lender of entering the CM with accepted bills, $d$, and $V\left(d^{\prime}\right)$ represent the value to a non-bank of starting the next period with accepted bills, $d^{\prime}$ we find:

$$
W^{l}(d)=\max _{X, d^{\prime}} X+\beta V\left(d^{\prime}\right)
$$

subject to the budget constraint:

$$
X+d^{\prime}=d
$$

The lender maximizes consumption in the $\mathrm{CM}$ and the discounted value of carrying $d^{\prime}$ into the next period FM subject to the constraint that the value of the accepted bills carried into the $\mathrm{CM}$ 
must equal the CM goods consumed and the value of the accepted bills carried into the next period. Substituting out for $X$, we find:

$$
W^{l}(d)=d+\max _{d^{\prime}}-d^{\prime}+\beta V\left(d^{\prime}\right)=d+W^{l}(0)
$$

The first order condition for the choice of $d^{\prime}$ is:

$$
1 \geq \beta V^{\prime}\left(d^{\prime}\right)
$$

with complementary slackness. Thus, this choice does not depend on the quantity of accepted bills brought into the CM. All lenders will carry the same quantity of accepted bills into the next period.

Observe that the envelop condition for this problem is:

$$
W_{d}^{l}=1
$$

Now consider the FM and the problem faced by a lender who brings bills, $d$, into the FM. After the realization of uncertainty at the start of the FM the lender's problem is

$$
\max _{q}-\frac{1}{2 A} q^{2}+W^{l}(d+p q)
$$

where $p$ is the price of the good in the FM market. That is, the lender chooses $q$ to maximize the sum of the costs incurred by producing $q$ and the value to the lender of carrying the proceeds of the sale of $q$ into the $\mathrm{CM}$. The first order condition for this problem is:

$$
-q / A+p W_{d}^{l}=0
$$

and an optimizing lender will choose:

$$
q^{*}(A, p)=p A
$$

Observe that the amount that lenders choose to produce does not depend on the quantity of bills that they bring into the market, but only on the value of the product and their productivity this period.

The Borrower's Problem: Turning to the borrower, observe that the borrower's value function in the CM depends on loans as well as accepted bills brought into the CM:

$$
W^{b}(\ell, d)=\max _{Q, d^{\prime}}-Q+\beta V\left(d^{\prime}\right)
$$




\section{SISSOKO The Nature of Money}

subject to the budget constraint

$$
d^{\prime}=Q+d-(1+i) \ell
$$

The borrower maximizes the sum of the cost of producing in the $\mathrm{CM}$ and the continuation value of carrying $d^{\prime}$ bills into the next period subject to the constraint that the value of the bills carried on must equal the quantity produced plus the value of bills less the expense to the borrower of paying off the loan. Observe that this expense has two components: the principal of the loan which is paid off by producing in exchange for acceptances that will be deposited in the issuer's account and the interest on the loan which may be paid by transferring real goods to the bank.

Just as in the case of the lender, this problem can be rewritten:

$$
\begin{gathered}
W^{b}(\ell, d)=d-(1+i) \ell+\max _{d^{\prime}}-d^{\prime}+\beta V\left(d^{\prime}\right) \\
=d-(1+i) \ell+W^{b}(0,0)
\end{gathered}
$$

And we find that once again the assets that are brought into the $\mathrm{CM}$ do not affect the choice of bills brought out of the CM. As a result both lenders and borrowers solve the same problem in the $\mathrm{CM}$, have the same first order condition, and will carry the same quantity of bills into the next period.

The envelop conditions for the borrower are:

$$
\begin{gathered}
W_{\ell}^{b}=-(1+i) \\
W_{d}^{b}=1
\end{gathered}
$$

These conditions determine the optimizing choices that a borrower will make when transacting with a bank in the FM. When a borrower brings accepted bills into the FM, the fact that $i \geq 0$ ensures that the borrower will prefer to spend the bills that were brought into the FM rather than holding them and taking out a loan to make up the difference.

First, we consider credit equilibria. In a credit equilibrium the borrower's stock of bills is insufficient to purchase the desired quantity and the borrower must take out a loan. Then, the borrower's problem is:

$$
\max _{x} x^{\alpha}+W^{b}(p x-d, 0)
$$

subject to:

$$
p x-d \leq \bar{\ell}
$$


where $\bar{\ell}$ is a borrowing constraint that is taken as given by the borrowers. That is the borrower maximizes the sum of his current period utility from consumption and the continuation value of spending all of his (matured and therefore non-interest bearing) bills and carrying an interestbearing loan in to the CM, subject to the constraint imposed by the bank on the size of the loan. The first order condition is then:

$$
\alpha x^{\alpha-1}+p W_{\ell}^{b}-p \lambda=0
$$

where $\lambda$ is the multiplier on the borrowing constraint. The borrower's optimal choice will be

$$
x^{*}(p)=\left\{\begin{array}{lr}
\left(\frac{\alpha}{p(1+i)}\right)^{\frac{1}{1-\alpha}} & \text { if } \lambda=0 \\
\frac{\bar{\ell}+d}{p} & \text { otherwise. }
\end{array}\right.
$$

That is, when the borrowing constraint does not bind there is an interior solution, and when the borrowing constraint does bind so that $\lambda>0$, the borrower will spend all available funds. Thus, there are two types of credit equilibria to consider: those in which there is slackness in the lending constraint, and those in which there is not.

When the lending constraint is non-binding, the market clearing price, $p(A)$, is:

$$
p(A)=\left(\frac{\alpha}{1+i}\right)^{\frac{1}{2-\alpha}}\left(\frac{1-n}{A n}\right)^{\frac{1-\alpha}{2-\alpha}}
$$

and expenditure on the FM good given $A$ is:

$$
\pi(i) A^{\frac{\alpha}{2-\alpha}}
$$

where

$$
\pi(i) \equiv\left(\frac{\alpha}{1+i}\right)^{\frac{2}{2-\alpha}}\left(\frac{n}{1-n}\right)^{\frac{\alpha}{2-\alpha}}
$$

Observe that when borrowing takes place unconstrained, a positive lending rate distorts consumption relative to the first best allocation: because interest must be paid on the borrowed funds, borrowers will prefer to reduce consumption of the FM good relative to the first-best.

By contrast when the credit constraint binds, the market clearing price, $p_{\ell}(A)$, is:

$$
p_{\ell}(A)=\left[\frac{(1-n)(\bar{\ell}+d)}{A n}\right]^{\frac{1}{2}}
$$




\section{SISSOKO The Nature of Money}

and expenditure on the FM good given $A$ is:

$$
\bar{\ell}+d
$$

Figure 1 depicts the sequence of events, the movement of commercial bills through the economy, and how the holdings of loans and bills change over time.

Figure 1- Timeline

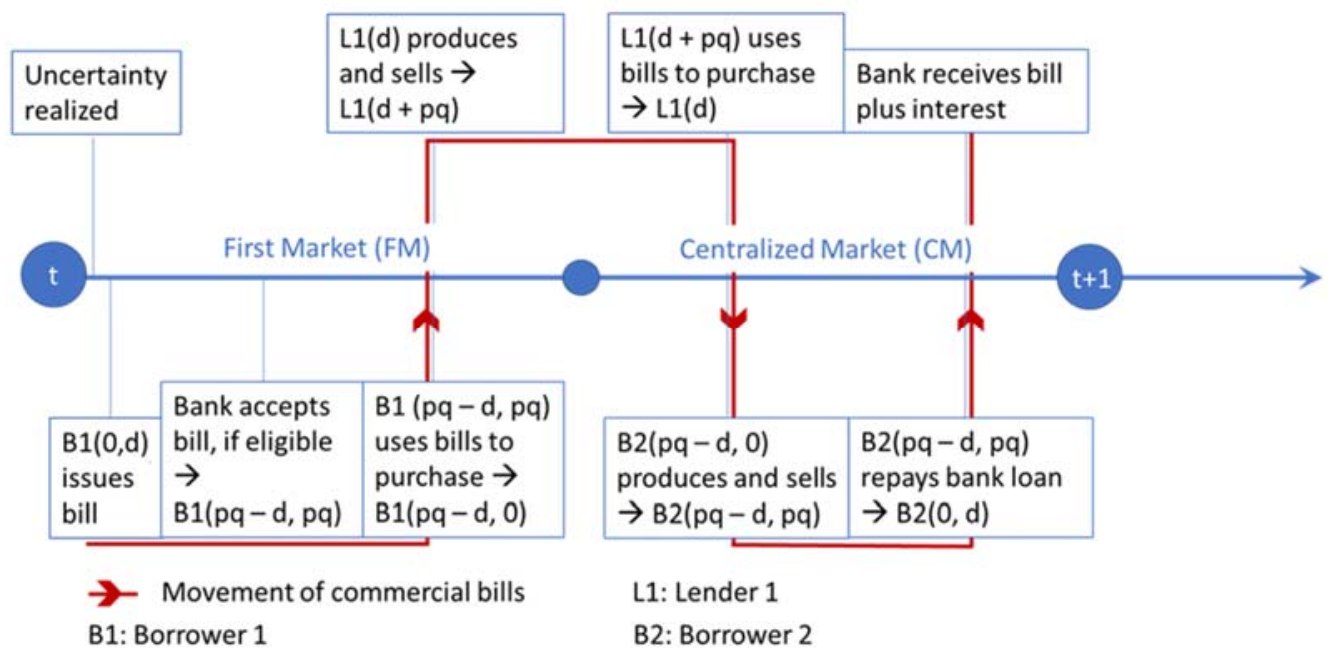

\section{Banks:}

Banks in our model set interest rates and credit limits, but otherwise respond passively to the economy's demand for accepted bills: they earn $i L$ where $L$ represents the aggregate quantity of loans. They are willing to lend to each borrower whatever $\ell \leq \bar{\ell}$ the borrower demands.

How is it possible for banks to "meet the needs of trade" by responding passively to the demand for bank credit? That is, how it is possible for a bank's balance sheet to expand to meet the demand for loans? This is explained by the fact that the accounting treatment for an accepted bill is typically "off-balance sheet." An accepted bill is a contingent bank liability that will only be payable if the original issuer of the bill defaults. Accounting norms in general do not require that a contingent liability be reported on balance sheet until it becomes probable that the contingency will be realized. ${ }^{6}$ For this reason, there is no requirement in this model that the quantity of loans must be backed by "deposits."

\footnotetext{
${ }^{6}$ For the off-balance-sheet treatment of accepted bills, see David Sheppard, The Growth and Role of U.K. Financial Institutions 1880 - 1962 at 117 Table (A)1.1 n.4 (1971).
} 
While under modern accounting practices accepted bills are typically off-balance sheet for a bank, an alternate convention that was sometimes followed in the $19^{\text {th }}$ century was to treat the accepted bills as both an asset and a liability. Thus, we "stack the deck" against banking by taking the more conservative view that accepted bills count against a bank's debt limit. That is, even though the quantity of loans that a bank can accept is not limited by the quantity of deposits placed with a bank, there is a limit on the quantity of loans that a bank can accept. This limit is analogous to the borrowing limit that is faced by non-banks: there is an endogenous debt limit, $\bar{b}$, that constrains the banks' liabilities - and accepted bills count against this constraint.

The banks' debt limit is generated by the fact that in the CM banks have the technology to circulate bills that are not related to non-bank transactions in order to purchase the consumption good. At the end of a period in which a bank circulates such bills, the bank is bankrupt, is found out, and is forced into autarky.

We analyze two types of equilibria: enforcement equilibria where the debt of both nonbanks and banks is exogenously enforceable, and equilibria without enforcement in which lending constraints must be used to guarantee the incentive compatibility of the repayment of debt.

\subsection{Stationary enforcement equilibrium}

In an enforcement equilibrium, because the debt of banks is exogenously enforceable, $\bar{b}=\infty$, and, because the debt of non-banks is exogenously enforceable, $\bar{\ell}=\infty$. There are two types of enforcement equilibria with credit to consider. (The derivation of the value functions is presented in Appendix 1.)

Type Ia: $d \leq \pi(i)$, borrowing takes place in all states. In a Type Ia environment the value function, $V^{I a}$, is:

$$
\begin{aligned}
V^{I a}(d)= & (1-n)^{\frac{2-2 \alpha}{2-\alpha}}\left(\frac{n \alpha}{1+i}\right)^{\frac{\alpha}{2-\alpha}}\left[1-\alpha+\frac{\alpha}{2(1+i)}\right]\left[(1-\sigma)+\sigma \bar{A}^{\frac{\alpha}{2-\alpha}}\right] \\
& +d[(1-n)(1+i)+n]+n W^{e p}(0)+(1-n) W^{l p}(0,0)
\end{aligned}
$$

Type Ib: $d \in\left[\pi(0), \pi(i) \bar{A}^{\frac{\alpha}{2-\alpha}}\right]$, borrowers borrow only when $\bar{A}$ is realized. In a Type Ib environment the value function, $V^{I b}$, is:

$$
\begin{gathered}
V^{I b}(d)=(1-n)^{\frac{2-2 \alpha}{2-\alpha}}(n \alpha)^{\frac{\alpha}{2-\alpha}}\left[(1-\sigma)\left(1-\frac{\alpha}{2}\right)+\sigma\left[1-\alpha+\frac{\alpha}{2(1+i)}\right]\left(\frac{\bar{A}}{1+i}\right)^{\frac{\alpha}{2-\alpha}}\right] \\
+d[\sigma(1-n)(1+i)+(1-\sigma(1-n))]+n W^{e p}(0)+(1-n) W^{l p}(0,0)
\end{gathered}
$$




\section{SISSOKO The Nature of Money}

In each environment the value function depends on FM consumption, the value that the stock of accepted bills, $d$, will make it possible to carry into the $\mathrm{CM}$, and the continuation value of the game. Observe that in an enforceable credit equilibrium consumption in the FM is independent of the level of $d$, but that when $i>0$ borrowers consume less than they would in the first best allocation. Observe also that in this environment where liquidity constraints don't bind, the principal effect of $d>0$ is to reduce the interest costs for borrowers. For this reason both value functions are linear in $d$ and the solution to the optimization problem, equation (3), is well-defined.

\section{Intertemporal Optimization}

In the Type Ia environment consumption in the FM is independent of $d$, and the first order condition for the value function is simply:

$$
V^{I a^{\prime}}(d)=1+(1-n) i
$$

Thus, the only effect of an incremental increase in $d$ when debt holdings are low is to generate a return equal to the value of carrying the bills into the next $\mathrm{CM}$ and the expected value of the interest that will be avoided by borrowers who increase their holdings of bills.

Of course, in order for this low level of debt to be a stationary equilibrium it must be the case that an agent optimizes in the CM, or that equation (4) is satisfied and therefore that the Type Ia agent prefers to spend all but $d$ of his deposits in the CM, or that:

$$
1 \geq \beta V^{I a^{\prime}}(d)=\beta[1+(1-n) i]
$$

or

$$
i \leq \frac{1-\beta}{\beta(1-n)} \equiv \hat{\imath}^{I a}
$$

Observe that only when the banks are able to coordinate on the highest optimizing interest rate, $\hat{\imath}^{I a}$, is a positive level of bill holdings consistent with equilibrium. Any measure of competition in the banking sector that results in a lower interest rate causes optimizing borrowers to prefer not to carry bills over time.

In the Type Ib environment, the Euler equation gives us the only level of $i$ that is consistent with an equilibrium in which borrowers borrow only if $\bar{A}$ is realized - and therefore carry enough bills into the FM to consume when $A=1$ is realized:

$$
\frac{1-\beta}{\sigma \beta(1-n)}=i \equiv \hat{\imath}^{I b}
$$


Definition 1: A bank money equilibrium with enforcement and borrowing is a set $(i, p(A), d, q(A), x(A))$ such that equations (2), (5), (6), (9) and (11) are satisfied.

Definition 2: A bank money equilibrium with enforcement and partial borrowing is a set $(i, p(A), d, q(A), x(A))$ such that equations (2), (5), (6), (10) and (12) are satisfied.

\section{Banks: How interest rates are chosen}

As was discussed above, banks do not choose the quantity of loans they wish to make, but instead set the interest rate and the borrowing constraints and then allow quantities to adjust given the prices that have been set. In an enforcement equilibrium, $\bar{b}=\infty$, and as a result there are no constraints on the quantity of loans that a bank can make.

Because banks choose price and not quantity, we analyze bank behavior using the framework of Bertrand competition. That is, we assume that each bank sets its interest rate, taking what it expects the other banks to do as given, and an equilibrium is found when each bank's strategy is a best response to the other banks' strategies.

In each period a bank chooses the interest rate to maximize the expected value of the lending rate multiplied by the loans that the bank expects to make, $\ell^{b}(i)$ :

$$
\max _{i} E i \ell^{b}(i)
$$

Because the banks under Bertrand competition simultaneously set the interest rate, $i$, that they will charge non-bankers, non-bankers will bring all of their business to the bank that posts the lowest interest rate. We assume that if more than one bank posts the lowest interest rate, then the market is split evenly between the banks offering the low rate. As is well established, the best response of a bank is to set the rate incrementally below the lowest rate set by the other banks if that rate is above cost and to set the rate at cost if the lowest rate is at cost. For this reason, the only Nash equilibrium in Bertrand competition is for banks to price their loans at cost. That is, the outcome of Bertrand competition is the competitive outcome.

Given this structure the logic of Bertrand competition will mean that all banks set $i=0$ since lending is a costless activity and any bank that expects the other banks to set higher rates will try to capture the whole market by setting a lower rate.

Observe that when banking is competitive, the left hand side of equation (11) is zero, and we can conclude that when banking is competitive equation (11) is an inequality and the only enforcement equilibrium has $d=0$. We state this formally as follows:

Proposition 1: When banking is competitive, $i=0$, and the only monetary equilibrium with enforcement has $d=0$ and is a bank money equilibrium with enforcement and borrowing. In this equilibrium, production and consumption are first-best, $q(A)=q^{* *}(A)$ and $x(A)=$ $x^{* *}(A)$. 
Proof: Because $\beta<1$, equation (12) cannot be satisfied when banking is competitive, so there are no equilibria with partial borrowing. To evaluate Type Ia equilibrium we substitute $i$ into (11), find that the left-hand side is zero, and thus that the equation holds as an inequality. Then in any equilibrium $d=0$. Substituting $d=i=0$ into equations (5) and (6), we find $q(A)=q^{* *}(A)$ and $x(A)=x^{* *}(A)$.

Observe also that the monetary equilibrium with enforcement and competitive banking gives the first-best outcome even though the Friedman Rule does not hold. In other words, when the monetary system is based on the one that existed in the $18^{\text {th }}$ century, the first-best outcome is possible in an environment with convertible currency - if debt is enforceable. In short, the Friedman Rule is not so much a general result, but instead an artifact of a particular way of modeling money. When one views the means of exchange - as it was viewed in the era of convertible currency ${ }^{7}$ - not as an asset, but as a debt on which interest had to be paid, the first best is possible as long as the cost of that debt is negligible.

\subsection{Stationary equilibrium without enforcement}

Now consider the case of equilibria without enforcement, where the repayment of debt must be incentive compatible for the agents in our economy. The non-bankers will face the credit constraint, $\bar{\ell}$, that ensures that they are never able to borrow so much that they would prefer to default rather than to pay back the debt. Similarly, the bankers will face the credit constraint, $\bar{b}$, which ensures that the value of being a banker is greater than the value of taking advantage of the special economic function of a banker in order to defraud the public and then suffer the consequences of bank failure.

Before calculating $\bar{b}$ and $\bar{\ell}$, we consider the problem faced by non-bankers. There are three possible types of environment without enforcement. (The derivation of the value functions is presented in Appendix 1.)

Type I: the non-bank borrowing constraint is slack

Type II: the non-bank borrowing constraint only binds when $\bar{A}$ is realized

Type III: the non-bank borrowing constraint always binds

Within the Type I environment, there may be sub-type "a" equilibria where non-banks borrow in every period, sub-type "b" equilibria where non-banks hold enough bills that they borrow only when productivity is high, and sub-type "c" equilibria where non-banks hold so many bills that they never borrow. A Type Ic equilibrium is the only one in which there is no borrowing. In the Type II environment, because the liquidity constraint binds in the high productivity state,

\footnotetext{
${ }^{7}$ See, e.g, Wicksell (1898), Dunbar (1909), Willis (1916).
} 
there can only be two sub-types of equilibria, "a" and "b," similarly all Type III equilibria are also sub-type "a" equilibria. The value functions for each of these six types of equilibria differ, and we start by focusing on the subtype "a" equilibria. The other types of equilibria will be considered at various points in the text. Each equilibrium is described by three equations: an intertemporal Euler equation, a non-bank incentive constraint, which both determines the level of $\bar{\ell}$ and incorporates the non-bank value function, and a bank incentive constraint which determines the minimum interest rate consistent with a bank borrowing constraint sufficiently high to support desired borrowing in the high productivity state.

\section{Type Ia equilibria}

The value function for the environment where the liquidity constraint never binds was derived above in the enforcement equilibria section. The relevant Euler equation is: $i \leq \frac{1-\beta}{\beta(1-n)} \equiv \hat{\imath}^{I a}$.

\section{The borrowing constraint for non-banks}

The borrowing constraint for the non-banks ensures that the repayment of debt is always incentive compatible. In the case of no default, a borrower pays back the loan with interest (after having spent in the FM any bills she brought into the FM) and gets the continuation value of the game, or:

$$
W^{b}(\ell, 0)=-(1+i) \ell+\beta V(d)
$$

By contrast, the value to a borrower of entering the $\mathrm{CM}$ with loan, $\ell$, and accepted bills, $d$, when the borrower intends to default is represented by $\widehat{W}^{b}(\ell, d)$. Default results in a loss of bank services and without bank support no other member of the economy will accept the defaulter's debt in payment, so the continuation value of the game is autarky. ${ }^{8}$ Furthermore, a defaulter chooses not to produce at a loss so:

$$
\widehat{W}^{b}(\ell, d)=-\hat{Q}+\beta \widehat{V}\left(\hat{d}^{\prime}\right)=0
$$

Then, the borrowing constraint for non-banks is:

$$
W^{b}(\bar{\ell}, 0) \geq \widehat{W}^{b}(\bar{\ell}, d)=0
$$

\footnotetext{
${ }^{8}$ This is similar to Gu, Mattesini, Monnet, \& Wright (2013) where the penalty to being caught in default is autarky. Note, however, that we do not adopt the whole of their framework. They assume that an agent is only caught defaulting with a certain probability. This does not accord with the role of banks discussed in this paper, although as a technical matter, such a probability can easily be added to the model.
} 


\section{SISSOKO The Nature of Money}

When this equation holds with equality, it can be rewritten as a fixed-point problem:

$$
\bar{\ell}=\frac{\beta V(d ; \bar{\ell})}{1+i}
$$

Let $\bar{\ell}^{*}$ denote the solution to this problem.

Lemma 1: Given $\bar{\ell}=\bar{\ell}^{*}, W^{b}(\ell, 0)$ is decreasing in $\ell$, and $W^{b}(\ell, 0) \geq \widehat{W}^{b}(\bar{\ell}, d)$ for all $\ell \leq$ $\bar{\ell}$.

Proof: $W^{b}(\ell, 0)=-(1+i) \ell+\beta V\left(d ; \bar{\ell}^{*}\right)$ and for all cases $V\left(d ; \bar{\ell}^{*}\right)$ is independent of $\ell$, the amount of debt that the borrower carries into the CM in the current period. As $W^{b}(\ell, 0)$ is decreasing in $\ell$ and is equal to zero at $\bar{\ell}^{*}, W^{b}(\ell, 0) \geq 0=\widehat{W}^{b}(\bar{\ell}, d)$ for all $\ell \leq \bar{\ell}^{*}$.

Before preceding to discuss the banks' problem, it is convenient to rewrite $d$, the bill holdings that are carried from one period to the next as a fraction, $\theta$, of the expected expenditure of the borrower in the unconstrained case:

$$
d=\theta \pi(i)\left[(1-\sigma)+\sigma \bar{A}^{\frac{\alpha}{2-\alpha}}\right]
$$

Define $\underline{\theta}$ as the fraction of the expected expenditure that would allow the borrower to purchase his optimal bundle in the low productivity state:

$$
\underline{\theta} \equiv \frac{1}{(1-\sigma)+\sigma \bar{A}^{\frac{\alpha}{2-\alpha}}}<1
$$

and define $\bar{\theta}$ similarly, but for the high productivity state:

$$
\bar{\theta} \equiv \frac{\frac{\alpha}{A^{2-\alpha}}}{(1-\sigma)+\sigma \bar{A}^{\frac{\alpha}{2-\alpha}}}>1
$$

\section{Banks: The Problem of Franchise Value}

Recall that banks have the technology to circulate their bills in the CM in order to purchase the $\mathrm{CM}$ good even though this will leave them insolvent. Recall also that in both the CM and the FM banks face the limit on their liabilities, $\bar{b}$. At the end of a period in which a bank circulates such fraudulent bills the bank is bankrupt and is forced into autarky. Here we discuss the banks' incentive compatibility constraint both under Bertrand competition and more generally. 
First, consider the steady state value of being a banker at the start of a period, which we will represent by $V^{b}(i)$, where $i$ is the steady state value of the interest rate. Then,

$$
V^{b}(i)=E W^{b}(L)
$$

where $W^{b}(L)$ is the value of being a banker at the start of the CM, given that loans $L$ were made in the FM. $V^{b}(i)$ is the expected value of $W^{b}(L)$ over both values of $A$. Furthermore

$$
W^{b}(L)=i L+\beta V^{b}(i)
$$

or the value of being a banker in the CM is the real interest owed to the bank plus the discounted continuation value of being a banker in the future. And we can conclude that:

$$
V^{b}(i)=\frac{i E L}{1-\beta}
$$

where $E L$ is the expected quantity of loans.

Let $\widetilde{W}(L)$ be the value of default to a banker who expects payment on loans outstanding, $L$, in the CM. Then:

$$
\widetilde{W}(L)=i L+\bar{b}-L
$$

or $\widetilde{W}(L)$ is given by the funds paid to the bank in exchange for the loan plus the value to the bank of issuing bills up to the bank's constraint, as the continuation value of default in the next period is autarkic and therefore zero. Recall that a bank must lend in the FM in order to be able to issue bills in the CM.

Banking is incentive compatible only if the bank will prefer not to default, when the bank's loans - and the interest to be paid on them - are at their lowest. In the type Ia environment incentive compatibility is given by:

$$
W^{b}((1-n)(\pi(i)-d)) \geq \widetilde{W}((1-n)(\pi(i)-d))
$$

In order for the banking system to have the borrowing capacity to support the market it must be the case that $\bar{b}$, the lending capacity of the banks, is sufficiently high

$$
\bar{b} \geq(1-\mathrm{n})\left(\pi(i) \bar{A}^{\frac{\alpha}{2-\alpha}}-d\right)
$$

$\bar{b}$ must therefore exceed the mass of borrowers times the maximum amount that they seek to borrow. Here we impose this borrowing capacity as a condition that must be met in order for the banking system to provide adequate banking services. Thus, after simplifying the banks' 


\section{SISSOKO The Nature of Money}

incentive compatibility constraint, substituting in the FM value function, and imposing the condition that $\bar{b}$ must be high enough that the bank can afford to fund the maximum level of loans, we find:

$$
\frac{\beta}{1-\beta} \frac{i E L}{\pi(i)(1-n)} \geq \bar{A}^{\frac{\alpha}{2-\alpha}}-1
$$

In a Type Ia equilibrium $\theta<\underline{\theta}<1$ and

$$
E L=(1-n)(1-\theta) \pi(i)\left[(1-\sigma)+\sigma \bar{A}^{\frac{\alpha}{2-\alpha}}\right]
$$

Plug this into equation (17) and define $\check{l}^{I a}$ to be the $i$ that solves equation (17) when it holds as an equality:

$$
i \geq \frac{1-\beta}{\beta(1-\theta)}(\bar{\theta}-\underline{\theta}) \equiv \breve{\imath}^{I a}
$$

Observe that in a Type Ia equilibrium as long as $i>0$, then there exists some value of $\beta$ such that the incentive compatibility constraint, equation (18), will be met for all $\beta$ greater than that value. Under Bertrand competition, however, $i=0$ and the Type Ia incentive compatibility constraint for bankers is always violated.

This indicates that banking is an incentive compatible profession only if bankers earn some positive rate of interest on their loans over and above the costs of making them. This is stated formally in Lemma 2.

Lemma 2: Competitive banking, where the interest rate reflects only the zero costs of banking, is not incentive compatible in a type I environment.

In addition, only when the banking sector is structured such that there is a franchise value to banking, $V^{b}(i)>0$, is bank provision of a reputation-based money supply incentive compatible. $^{9}$

Given that under Bertrand competition there can be no equilibrium in a type I environment, we now characterize the set of possible equilibria without the assumption that the banking sector is competitive, and then in Section IV discuss means by which policy can choose one of these equilibria.

\footnotetext{
${ }^{9}$ Charles Goodhart observes that this framework omits an alternative enforcement mechanism: early $20^{\text {th }}$ century banking developed in an environment where the assets of wealthy bankers were at risk, and there is indeed little doubt that the actual enforcement mechanisms used in the past were more complicated than those in the model.
} 
Definition 3: A bank money equilibrium with unconstrained credit and borrowing in all states (Type Ia equilibrium) is a set $(i, p(A), d, q(A), x(A), \bar{\ell}, \bar{b})$ such that the resource and intratemporal optimization conditions, equations (2), (5), and (6), intertemporal optimization, equation (11), and the incentive compatibility constraints, equations (13) and (18), are satisfied, $\pi(i) \bar{A}^{\frac{\alpha}{2-\alpha}} \leq \bar{\ell}+d$, and $d<\pi(i)$.

In a Type Ia equilibrium the Euler, equation (11), tells us that either $d=0$ and the equation sets an upper bound on $i$ or $d>0$ and $i=\hat{\imath}^{I a}$. The bank incentive constraint, equation (18), sets a lower bound on $i, \breve{l}^{I a}$. Lemma 3 then defines some of the characteristics of a Type Ia equilibrium.

Lemma 3: If the non-bank borrowing constraint never binds and $d=\theta=0$, then when $n+$ $\sigma \geq 1$ there exists $i$ such that $\hat{\imath}^{I a} \geq i \geq \breve{l}^{I a}$, and when $n+\sigma<1$, there exists $i$ such that $\hat{\imath}^{I a} \geq$ $i \geq \breve{l}^{I a}$, if

$$
\bar{A} \leq\left(\frac{2-n-\sigma}{1-n-\sigma}\right)^{\frac{2-\alpha}{\alpha}}
$$

Proof: When the non-bank borrowing constraint never binds and $d=\theta=0$,

$$
\frac{1-\beta}{\beta} \frac{1}{1-n} \equiv \hat{\imath}^{I a} \geq \breve{\imath}^{I a} \equiv \frac{1-\beta}{\beta} \frac{\bar{A}^{\frac{\alpha}{2-\alpha}}-1}{(1-\sigma)+\sigma \bar{A}^{\frac{\alpha}{2-\alpha}}}
$$

which can be rewritten:

$$
(2-n-\sigma) \geq(1-n-\sigma) \bar{A}^{\frac{\alpha}{2-\alpha}}
$$

The two results follow.

The steady state value function that incorporates equations (2), (5), and (6) in a Type Ia environment is given by:

$$
V^{I a}(d)=\frac{1}{1-\beta}(1-n)^{\frac{2-2 \alpha}{2-\alpha}}\left(\frac{n \alpha}{1+i}\right)^{\frac{\alpha}{2-\alpha}}\left[1-\alpha+\frac{\alpha(1+2 \theta i)}{2(1+i)}\right]\left[(1-\sigma)+\sigma \bar{A}^{\frac{\alpha}{2-\alpha}}\right]
$$


Plug this into equation (13) to get:

$$
\bar{\ell}^{* I a}=\frac{\beta}{1-\beta}(1+i)^{\frac{-2}{2-\alpha}}(1-n)^{\frac{2-2 \alpha}{2-\alpha}}(n \alpha)^{\frac{\alpha}{2-\alpha}}\left[1-\alpha+\frac{\alpha(1+2 \theta i)}{2(1+i)}\right]\left[(1-\sigma)+\sigma \bar{A}^{\frac{\alpha}{2-\alpha}}\right]
$$

Confirm that the assumption that the non-bank borrowing constraint does not bind is met or that

$$
\bar{\ell}^{*} \geq\left[\frac{\alpha}{1+i}\right]^{\frac{2}{2-\alpha}}\left[\frac{(1-n)}{n}\right]^{\frac{-\alpha}{2-\alpha}}\left(\bar{A}^{\frac{\alpha}{2-\alpha}}-\theta\left[(1-\sigma)+\sigma \bar{A}^{\frac{\alpha}{2-\alpha}}\right]\right)
$$

This inequality simplifies:

$$
\frac{\beta(1-n)}{1-\beta}\left[\frac{1-\alpha}{\alpha}+\frac{(1+2 \theta i)}{2(1+i)}\right] \geq \bar{\theta}-\theta
$$

In the case where no bills are carried from one period to the next, $\theta=0$ and the inequality simplifies even further:

$$
\frac{1}{1+i} \geq 2\left(\frac{\bar{\theta}}{1-n} \frac{1-\beta}{\beta}-\frac{1-\alpha}{\alpha}\right)
$$

Proposition 2: Given $d=\theta=0$ and $n+\sigma \geq 1$ or $n+\sigma<1$ and $\bar{A} \leq\left(\frac{2-n-\sigma}{1-n-\sigma}\right)^{\frac{2-\alpha}{\alpha}}$, then the set of interest rates consistent with bank money equilibrium with unconstrained credit is given by $\left\{i \mid \hat{\imath}^{I a} \geq i \geq \breve{\imath}^{I a}\right.$ and (20) holds $\}$ and there exists a critical value $\hat{\beta}^{I 0}$ such that a bank money equilibrium with unconstrained credit exists for all $\beta \geq \hat{\beta}^{I 0}$.

Proof: By Lemma 3 there exists $i$ such that equations (11) and (18) hold or $\hat{l}^{I a} \geq i \geq \breve{l}^{I a}$. The Type Ia value function, equation (9), incorporates equations (2), (5) and (6) and, in turn, is incorporated with equation (13) into equation (20). Thus, the set of Type la equilibrium interest rates is described by equations (11), (18), and (20) or $\left\{i \mid \hat{\imath}^{I a} \geq i \geq \breve{l}^{I a}\right.$ and (20) holds $\}$.

The right hand side of equation (20) is decreasing in $\beta$, converges to $\infty$ as $\beta$ converges to zero, and converges to a negative number as $\beta$ converges to one. Thus, there exists $\hat{\beta}^{I 0}$ such that equation (20) holds with equality when $i=\hat{\imath}^{I a}$. Now consider $\beta^{\prime} \geq \hat{\beta}^{I 0}$. By equations (11) and (18), $\beta^{\prime}$ defines new values $\hat{\imath}^{\prime}<\hat{l}^{I a}$ and $\breve{l}^{I^{\prime}}<\breve{l}^{I a}$, but does not change the relationship between them, so $\hat{\imath}^{\prime} \geq \breve{l}^{I^{\prime}}$. Plugging $\hat{\imath}^{\prime}$ into equation (20) we find that the right hand side has 
increased and the left hand side has decreased so the equation still holds. Conclusion: a bank money equilibrium with unconstrained credit exists for all $\beta \geq \hat{\beta}^{I 0}$.

When bills are held over time in equilibrium, less is borrowed from the banks and as a result interest rates must be higher than in the $\theta=0$ case in order for the bank incentive constraint to hold - as equation (18) demonstrates.

Lemma 4: If the non-bank borrowing constraint never binds and $\theta>0$, then iff $\theta \leq 1-$ $(1-n)(\bar{\theta}-\underline{\theta}) \equiv \hat{\theta}$ there exists $i$ such that $\hat{\imath}^{I a}=i \geq \breve{\imath}^{I a}$. Furthermore,

$$
\begin{aligned}
& \underline{\theta}=\hat{\theta} \quad \text { if } n+\sigma=1 \\
& \underline{\theta}>\hat{\theta} \quad \text { if } n+\sigma<1 \\
& \underline{\theta}<\hat{\theta} \text { if } n+\sigma>1
\end{aligned}
$$

Proof: There exists i such that $\hat{\imath}^{I a}=i \geq \breve{\imath}^{I a}$ iff

$$
\frac{1-\beta}{\beta} \frac{1}{1-n} \equiv \hat{\imath}^{I a} \geq \breve{l}^{I a} \equiv \frac{1-\beta}{\beta(1-\theta)}(\bar{\theta}-\underline{\theta})
$$

which can be rewritten:

$$
1-(1-n)(\bar{\theta}-\underline{\theta}) \geq \theta
$$

The equation

$$
1-(1-n)(\bar{\theta}-\underline{\theta}) \leq \underline{\theta}
$$

can in turn be rewritten

$$
1-\sigma-n \leq \bar{A}^{\frac{\alpha}{2-\alpha}}(1-\sigma-n)
$$

The three results relating $\underline{\theta}$ to $\hat{\theta}$ follow.

A bank money equilibrium with unconstrained credit can only exist if the non-bank liquidity constraint does not bind in the high productivity state. In the case where $\theta \geq 0$, we use the Euler, equation (11), to determine $i$, plug that into equation (19) and solve for $\theta$. This defines a function $\phi$, such that a Type Ia equilibrium can exist only if $\phi \leq \theta$. 


$$
\begin{gathered}
\text { SISSOKO The Nature of Money } \\
\phi(\alpha, \beta, n, \bar{\theta}) \equiv\left[\bar{\theta}-\frac{\beta(1-n)}{1-\beta}\left(\frac{1-\alpha}{\alpha}-\frac{\beta(1-n)}{2(1-\beta n)}\right)\right] \frac{(1-\beta n)}{1+\beta(1-2 n)} \leq \theta
\end{gathered}
$$

Proposition 3: Bank money equilibria with unconstrained credit, borrowing in every state, and $\theta>0$ are characterized by:

$$
\begin{gathered}
i=\hat{\imath}^{I a}=\frac{1-\beta}{\beta(1-n)} \\
\phi(\alpha, \beta, n, \bar{\theta}) \leq \theta \leq \min (\hat{\theta}, \underline{\theta})
\end{gathered}
$$

(i) For $\alpha<\frac{2}{3}$ and $\theta \leq \min (\hat{\theta}, \underline{\theta})$ there exists a critical value $\hat{\beta}^{I a}$ such that a bank money equilibrium with unconstrained credit exists for all $\beta \geq \hat{\beta}^{I a}$;

(ii) For $\alpha<\frac{2}{3}$ there exists a critical value, $\tilde{\beta}$, below which there is no $\theta$ that will support a Type Ia equilibrium. For $\alpha<\frac{2}{3}$ and $\tilde{\beta} \leq \beta$, there exists a critical value $\tilde{\theta}$ such that a Type Ia equilibrium exists for all $\tilde{\theta} \leq \theta \leq \min (\hat{\theta}, \underline{\theta})$

Proof: When $\theta>0$, the Euler, equation (11) must hold with equality, fixing $i=\hat{\imath}^{I a}$. By Lemma 4 , for $\theta \leq \hat{\theta}, \hat{\imath}^{I a} \geq \breve{l}^{I a}$ and equation (18) is also met. Equations (2), (5), (6) and (13) are incorporated into equation (21) which defines a lower bound for $\theta$.

(i) To find $\hat{\beta}^{I a}$, consider equation (21):

$$
\phi(\alpha, \beta, n, \bar{\theta}) \leq \theta
$$

When $\alpha<\frac{2}{3}, \phi$ is continuously decreasing in $\beta$. As $\beta$ converges to one, $\phi$ converges to $-\infty$ for $\alpha<\frac{2}{3}$, and equation (21) is true. As $\beta$ converges to $0, \phi$ converges to $\bar{\theta}$ and for $\theta \leq$ $\min (\hat{\theta}, \underline{\theta})$ equation $(21)$ is false. Thus, when $\alpha<\frac{2}{3}$ for any given $\theta \leq \min (\hat{\theta}, \underline{\theta})$, there exists some $\hat{\beta}^{I a}$, such that $\phi(\alpha, \beta, n, \bar{\theta})=\theta$. Because when $\alpha<\frac{2}{3}, \phi(\alpha, \beta, n, \bar{\theta})$ is continuously decreasing in $\beta$, equation (21) will be true for all $\beta \geq \hat{\beta}^{I a}$.

(ii) When $\alpha<\frac{2}{3}, \tilde{\beta}$ is found by setting

$$
\phi(\alpha, \beta, n, \bar{\theta})=\min (\hat{\theta}, \underline{\theta})
$$

Using an argument analogous to the preceding argument, we find that a $\tilde{\beta}$ which solves this equation must exist. Furthermore, because $\phi(\alpha, \beta, n, \bar{\theta})$ is continuously decreasing in $\beta$, when $\alpha<\frac{2}{3}, \phi$ will be greater than $\min (\hat{\theta}, \underline{\theta})$ for all $\beta<\tilde{\beta}$, and thus for $\operatorname{such} \beta$ there exists no $\theta \leq$ 
$\min (\hat{\theta}, \underline{\theta})$ such that equation (21) is true. When $\alpha<\frac{2}{3}$ and $\beta \geq \tilde{\beta}, \phi(\alpha, \beta, n, \bar{\theta}) \leq$ $\min (\hat{\theta}, \underline{\theta})$. Set $\tilde{\theta}=\max (0, \phi)$. Then equation (21) is true for all $\tilde{\theta} \leq \theta \leq \min (\hat{\theta}, \underline{\theta})$.

\section{Type Ib and Ic equilibria}

Definition 4: A bank money equilibrium with unconstrained credit and borrowing in the high productivity state (Type $\mathrm{Ib}$ equilibrium) is a set $(i, p(A), d, q(A), x(A), \bar{\ell}, \bar{b})$ such that the resource and intra-temporal optimization conditions, equations (2), (5), and (6), intertemporal optimization, equation (12), and the incentive compatibility constraints, equations (13) and (17), are satisfied, $\pi(i) \bar{A}^{\frac{\alpha}{2-\alpha}} \leq \bar{\ell}+d$, and $\pi(i) \leq d<\pi(i) \bar{A}^{\frac{\alpha}{2-\alpha}}$.

Definition 5: A bank money equilibrium with unconstrained credit and no borrowing (Type Ic equilibrium) is a set $(i, p(A), d, q(A), x(A), \bar{\ell}, \bar{b})$ such that the resource and intra-temporal optimization conditions, equations (2), (5), and (6), intertemporal optimization, and the incentive compatibility constraints for both banks and non-banks are satisfied, and $\pi(i) \bar{A}^{\frac{\alpha}{2-\alpha}} \leq$ $d$.

The value functions for Type Ib and Type Ic equilibria are derived in Appendix 1. The result in Lemma 5 is unsurprising:

Lemma 5: No Type Ic equilibria, in which $\theta \geq \bar{\theta}$ and agents never borrow, exist.

Proof: When $\theta>0$, the Euler equation must hold with equality. In this environment where there is no borrowing the Euler would be $\frac{1}{\beta}=1$, which is a contradiction.

In order for a Type Ic equilibrium to exist, non-bankers would have to carry bills from one period to the next even though these bills purchase the same quantity of goods in each period. Discounting ensures that this is never an optimizing choice.

In a Type Ib equilibrium, borrowing only takes place in the high productivity state, and as a result the economy only needs to support a single level of borrowing. For this reason, it is possible to set the bank borrowing constraint equal to the desired borrowing of the non-bankers in the high productivity state. Because only banks that lend in the FM can issue liabilities and default in the $\mathrm{CM}$, the fact that a tight borrowing constraint can be imposed on the bankers ensures that the problem of bank default can be eliminated without adversely affecting the allocation of the non-bankers. For this reason, the bank borrowing constraint is not a binding constraint in a Type $1 \mathrm{~b}$ equilibrium. 


\section{SISSOKO The Nature of Money}

Thus, a Type Ib equilibrium is determined by three equations, $\underline{\theta}<\theta \leq \bar{\theta}$, the Euler, $i=$ $\hat{\imath}^{l b}$, and $\phi^{b} \leq \theta$, where $\phi^{b}$ is found by the same procedure as $\phi$ : the $V^{I b}$ value function is plugged into equation (13), which is solved for $\bar{\ell}^{*}$. Then the non-binding liquidity constraint condition is imposed and the resulting inequality is solved for $\theta$. Finally $\hat{l}^{l b}$ is plugged into the equation. From this we find:

Proposition 4: Bank money equilibria with unconstrained credit and $\underline{\theta}<\theta \leq \bar{\theta}$ are characterized by:

$$
\begin{gathered}
i=\hat{\imath}^{I b}=\frac{1-\beta}{\sigma \beta(1-n)} \\
\phi^{b}(\alpha, \beta, n, \bar{\theta}) \equiv \bar{\theta}\left(2-\frac{1}{\alpha}+\hat{\imath}^{I b}\right)-\left(\frac{1}{\alpha}-\frac{1}{2}\right)\left(\frac{1}{\hat{\imath}^{I b}}\right)\left[\bar{\theta}+\underline{\theta} \frac{(1-\sigma)}{\sigma}\left(1+\hat{\imath}^{I b}\right)^{\frac{2}{2-\alpha}}\right] \leq \theta
\end{gathered}
$$

Proof: When $\theta>\underline{\theta}$, the Euler, equation (12) must hold with equality, fixing $i=\hat{\imath}^{I b}$. Equations (2), (5), (6) and (13) are incorporated with the condition that the liquidity constraint must not bind to find $\phi^{b}$ which defines a lower bound for $\theta$.

\section{Type IIa equilibria}

In the Type IIa environment $\bar{\ell}$ only binds when $\bar{A}$ is realized, but borrowing takes place in both states. The related value function (derived in Appendix 1) for non-banks is:

$$
\begin{aligned}
V^{I I a}(d)=(1- & \sigma)\left(\frac{n \alpha}{1+i}\right)^{\frac{\alpha}{2-\alpha}}(1-n)^{\frac{2-2 \alpha}{2-\alpha}}\left[1-\alpha+\frac{\alpha}{2(1+i)}\right] \\
& +(1-\sigma) d[(1-n)(1+i)+n]+\sigma(1-n)^{\frac{2-\alpha}{2}}[n \bar{A}(\bar{\ell}+d)]^{\frac{\alpha}{2}} \\
& +\sigma\left[n d-(1-n)(1+i) \bar{\ell}+\frac{(1-n)(\bar{\ell}+d)}{2}\right]+(1-n) W^{l p}(0,0) \\
& +n W^{e p}(0)
\end{aligned}
$$

When $V^{I I}(d)$ is lagged one period, simplified, and plugged into the CM optimization problem, we get: 


$$
\begin{aligned}
W^{e p}(d)=d+ & \beta\left[(1-\sigma)\left(\frac{n \alpha}{1+i}\right)^{\frac{\alpha}{2-\alpha}}(1-n)^{\frac{2-2 \alpha}{2-\alpha}}\left[1-\alpha+\frac{\alpha}{2(1+i)}\right]\right. \\
& \left.-\sigma \bar{\ell}\left[\frac{1-n}{2}+(1-n) i^{\prime}\right]+(1-n) W^{l p}(0,0)+n W^{e p}(0)\right] \\
& +\max _{d^{\prime}}\left\{-d^{\prime}+\beta d^{\prime}\left[\left(1-\sigma \frac{1-n}{2}\right)+(1-\sigma)(1-n) i^{\prime}\right]\right. \\
& \left.+\beta \sigma(1-n)^{\frac{2-\alpha}{2}}\left[n \bar{A}\left(\bar{\ell}+d^{\prime}\right)\right]^{\frac{\alpha}{2}}\right\}
\end{aligned}
$$

Before proceeding to solve the optimization problem, observe first that the maximization problem solved by borrowers in the CM is the same as that solved by lenders, and second that the second derivative in terms of $d^{\prime}$ of the optimization problem is negative, so the solution to the problem is well defined. Take the FOC to find the following Euler equation:

$$
\frac{1}{\beta}-1 \geq(1-\sigma)(1-n) i^{\prime}-\sigma \frac{(1-n)}{2}+\frac{\alpha \sigma}{2}(n \bar{A})^{\frac{\alpha}{2}}\left[\frac{1-n}{\bar{\ell}+d \prime}\right]^{\frac{2-\alpha}{2}}
$$

A monetary equilibrium with no accepted bill holdings from one period to the next will exist only if the marginal benefit of spending an accepted bill in the CM exceeds the marginal benefit of carrying it into the next period. The latter marginal benefit is given by the right hand side of equation (22) and is composed of the interest benefit earned by a borrower when productivity is low and the cost incurred by a borrower when productivity is high and the bills are not carried into the next period together with the incremental benefit due to a higher level of consumption when the liquidity constraint binds.

Equation (22) can be used to define the maximum lending rate that is consistent with borrower optimization in a Case IIa equilibrium, $\hat{\imath}^{\text {IIa }}$ :

$$
\left\{\frac{1}{\beta}-1+\sigma \frac{(1-n)}{2}-\frac{\alpha \sigma}{2}(n \bar{A})^{\frac{\alpha}{2}}\left[\frac{1-n}{\bar{\ell}+d l}\right]^{\frac{2-\alpha}{2}}\right\} \frac{1}{(1-\sigma)(1-n)} \equiv \hat{\imath}^{I I a} \geq i
$$

In the Type IIa environment equation (15) still defines bank incentive compatibility. However, both the expected loans in the high productivity state and the minimum level of $\bar{b}$ to support the equilibrium are given by $(1-n) \bar{\ell}$. Thus, the bank incentive constraint is given by:

$$
\frac{\beta i}{1-\beta}[(1-\sigma)(\pi(i)-d)+\sigma \bar{\ell}] \geq \bar{\ell}-(\pi(i)-d)
$$




\section{SISSOKO The Nature of Money}

Definition 6: A bank money equilibrium with partially constrained credit and debt in all states (Type IIa equilibrium) is a set $(i, p(A), d, q(A), x(A), \bar{\ell}, \bar{b})$ such that the resource and intratemporal optimization conditions, equations (2), (5), and (6), intertemporal optimization, equation (23), and the incentive compatibility constraints, equations (13) and (24), are satisfied, and $\pi(i) \leq \bar{\ell}+d \leq \pi(i) \bar{A}^{\frac{\alpha}{2-\alpha}}$.

Type IIa equilibria can only be evaluated numerically by solving jointly for $i$ and $\bar{\ell}$. Diagram 2 (in the next section) shows a typical region of equilibrium for the case where there are no bill holdings. Diagram 4 (also in the next section) shows the same for positive bill holdings. Type IIb equilibria can also only be found numerically. All efforts to find such an equilibrium have, however, failed.

\section{Type III equilibrium}

The value function for a Type III equilibrium in which the liquidity constraint always binds is:

$$
\left.V^{I I I}(d)=\frac{1}{1-\beta}\left\{(1-n)^{\frac{2-\alpha}{2}}[n \bar{\ell}+d)\right]^{\frac{\alpha}{2}}\left[(1-\sigma)+\sigma(\bar{A})^{\frac{\alpha}{2}}\right]-(1-n)\left(\frac{\bar{\ell}+d}{2}+i \bar{\ell}\right)\right\}
$$

From this we derive the Euler equation:

$$
\frac{1}{\beta}-1+\frac{(1-n)}{2}-\frac{\alpha}{2} n^{\frac{\alpha}{2}}\left[\frac{1-n}{\bar{\ell}+d^{\prime}}\right]^{\frac{2-\alpha}{2}}\left[(1-\sigma)+\sigma(\bar{A})^{\frac{\alpha}{2}}\right] \geq 0
$$

and plugging the value function into equation (13) we get the non-bank incentive constraint:

$\bar{\ell} \leq \frac{\beta}{(1-\beta)(1+i)}\left\{(1-n)^{\frac{2-\alpha}{2}}[n(\bar{\ell}+d)]^{\frac{\alpha}{2}}\left[(1-\sigma)+\sigma(\bar{A})^{\frac{\alpha}{2}}\right]-(1-n)\left(\frac{\bar{\ell}+d}{2}+i \bar{\ell}\right)\right\}$

In the Type III environment lending in every period is given by $(1-n) \bar{\ell}$, and as a result the minimum lending capacity of the banks, $\bar{b}$, is also $(1-n) \bar{\ell}$. This gives the Type III bank incentive constraint:

$$
\frac{\beta}{1-\beta} i \bar{\ell} \geq 0
$$

Observe that in this environment as in the Type $\mathrm{Ib}$ environment the equation used to determine the minimum interest rate consistent with bank incentive compatibility tells us nothing. Because the bank lending constraint can be set equal to the amount that will be borrowed whenever borrowing takes place and banks that do not lend in the FM cannot circulate liabilities in the 
$\mathrm{CM}$, there is no need for excess capacity upon which banks can default - and even an interest rate of 0 is consistent with equilibrium.

Definition 7: A bank money equilibrium with always-constrained credit (Type III equilibrium) is a set $(i, p(A), d, q(A), x(A), \bar{\ell}, \bar{b})$ such that the resource and intra-temporal optimization conditions, equations (2), (5), and (6), intertemporal optimization, equation (25), and the incentive compatibility constraints, equations (13) and (27), are satisfied, and $\bar{\ell}+d \leq \pi(i)$.

Proposition 5: Given $d=0$, there exists a critical value $\hat{\beta}^{I I I 0}$ such that no bank money equilibrium with always-constrained credit exists for all $\beta \geq \hat{\beta}^{I I I 0}$.

Proof: First, solve equation (26) to find $\bar{\ell}^{*}$ when $d=0$, and impose the condition that $\bar{\ell}^{*}$ is less than desired expenditure in the low productivity state. Solve this condition for $\beta$ to find:

$$
\beta \leq 2\left\{\frac{1+n i}{1+i}+n+\frac{2}{\alpha}\left[(1-\sigma)+\sigma(\bar{A})^{\frac{\alpha}{2}}\right](1-n)\right\}^{-1} \equiv \hat{\beta}^{I I I 0}
$$

\section{Equilibria in Diagrams}

Diagrams 2 through 5 allow us to visualize the set of stationary equilibria that exist in this convertible currency world. Unsurprisingly the level of bill holdings that supports the broadest range of equilibrium interest rates is the corner solution, no bill holdings at all.

When no bills are carried, the monetary system relies only on the "as needed" issue of credit to support the transactions of the economy. Because of the absence of a stock of a monetary asset, demand and supply do not fully determine the interest rate in equilibrium. Instead incentive constraints place upper and lower bounds on the set of equilibrium interest rates. In the next section, means by which the interest rate may be determined are discussed along with the policy implications of such choices.

Diagram 2 shows that when bills are not carried over time, $\beta$ is an important determinant of the type of equilibrium that can be supported. For the highest values of $\beta$, the only equilibria that exist are Type I equilibria where non-banks never face binding liquidity constraints. 


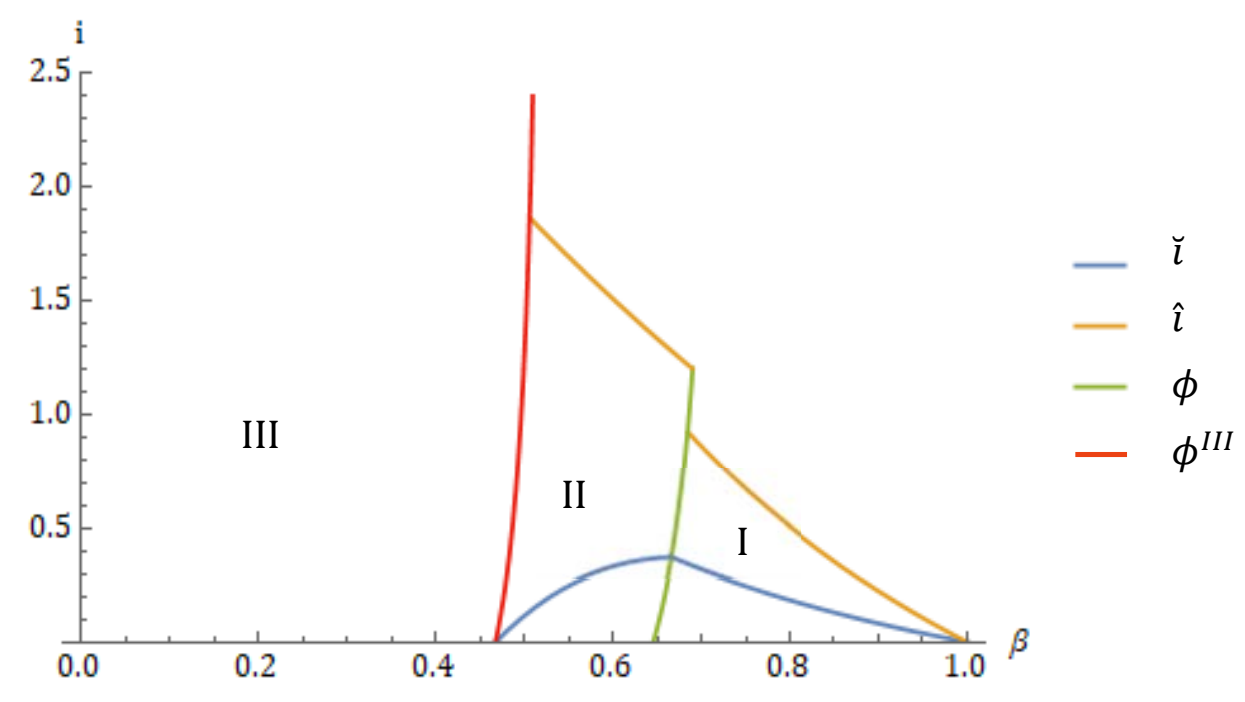

In a Type I equilibrium the bank incentive compatibility constraint defines a minimum interest rate (the blue line) that is adequate to induce the banks not to opt to take one-time advantage in the low productivity state of their ability to issue money up to the level needed to support production in the high productivity state, consume the proceeds, and then default. Similarly, the intertemporal Euler condition defines the level of interest (the yellow line) that is consistent with non-banks choosing to carry bills from one period to the next. In equilibria where nonbanks carry no bills over time interest rates may lie below the yellow line.

The green line, $\phi$, defines the boundary where $\bar{\ell}^{*}$, the minimum non-bank borrowing constraint, is just equal to the desired expenditure in the high productivity state. The red line, $\phi^{I I I}$, defines the boundary where $\bar{\ell}^{*}$ is just equal to the desired expenditure in the low productivity state.

When $\beta$ takes on a middling value, the only type of equilibrium with no bill holdings that exist are the Type II equilibria where non-banks are liquidity constrained in the high productivity state, but not in the low productivity state. For the Type II equilibria it is once again the case that the minimum level of the equilibrium interest rate is determined by the bank incentive constraint, while the maximum level is defined by the non-banks' intertemporal Euler equation.

For the lowest values of $\beta$ only Type III equilibria, where non-banks are liquidity constrained in all states, can be supported, and virtually any interest rate is a candidate for equilibrium. This latter result is due to the fact that on the one hand the same amount is borrowed in every state allowing the bank borrowing constraint to be set tightly, giving the 
banks no opportunity to issue liabilities in the $\mathrm{CM}$ and then default, and making the lower bound on the equilibrium interest rate zero; and on the other hand, non-banks are liquidity constrained in all states, so at the margin the interest rate doesn't play a role in the choice of how many bills to carry from one period to the next. Thus, in a Type III equilibrium the principal effect of raising interest rates is to reduce $\bar{\ell}^{*}$, the maximum size of the credit line that it is incentive compatible for non-banks to repay. (Note that the equilibrium level of $\bar{\ell}^{*}$ and how it changes is not depicted in Diagram 2.)

Diagram 3 depicts the welfare associated with the equilibria in Diagram 2. Non-bank welfare is highest when the interest rate is at the lowest equilibrium level. The blue line represents this case, while the green line represents non-bank welfare when the interest rate is at its maximum. Bank welfare when the interest rate is at its minimum is represented by the yellow line, and bank welfare when the interest rate is at its maximum by the red line. Note also that because there is no maximum interest rate in the Type III environment, in this case the highest value of the maximum interest rate for the Type II case was used instead.

The most obvious implication of Diagram 3 is that not only the borrowers, but also the bankers are better off in environments where liquidity constraints are slack than where they are binding.

Diagram 4 depicts the equilibria in which bills are held over time, focusing on the case of a moderate value of $\beta$ such that at $\theta=0$ the only equilibrium is a Type IIa equilibrium. The red line represents the Type IIa equilibria that exist when $\theta$ is low. These exist only up to the green dashed line, $\phi$, which is where $\bar{\ell}^{*}$ equals the desired expenditure in the high productivity state. When $\theta$ is high enough to lie on the other side of $\phi$, but is less than $\underline{\theta}$, the equilibria are Type Ia and have $i=\hat{\imath}^{I a}$. (Note that this diagram depicts the case where $n=\sigma=0.5$, so $\underline{\theta}=\hat{\theta}$ by

\section{Diagram 3- Welfare in Equilibrium: No Bill Holdings}

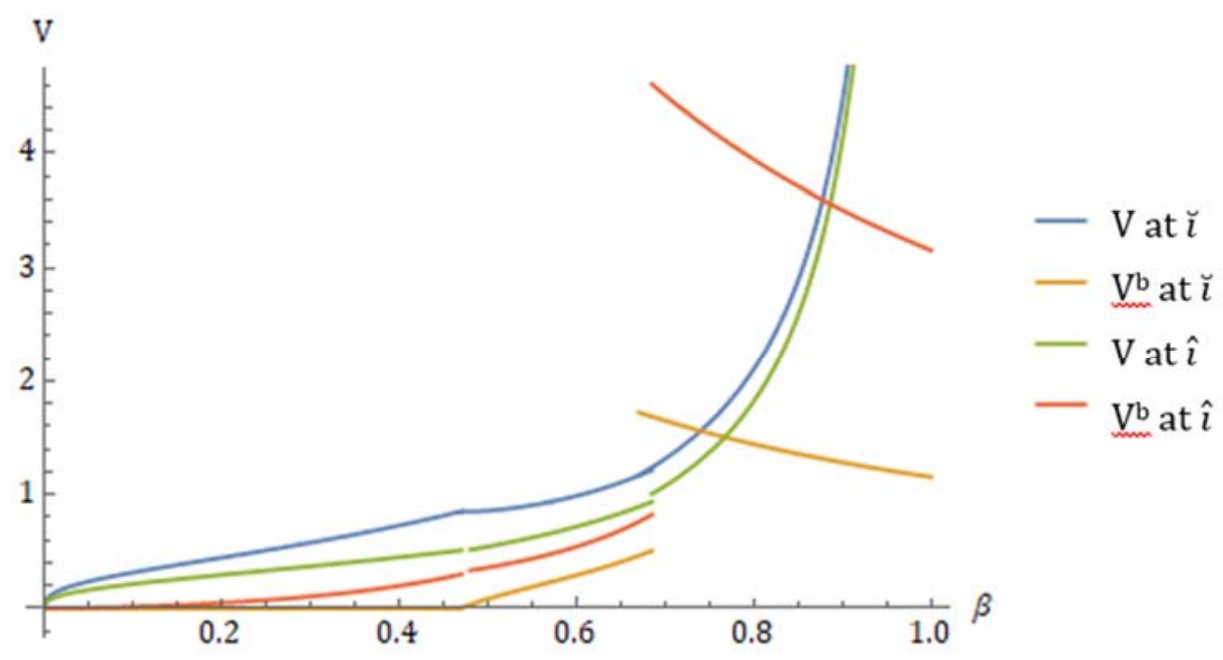


Diagram 4- Regions of Equilibrium: With Bill Holdings

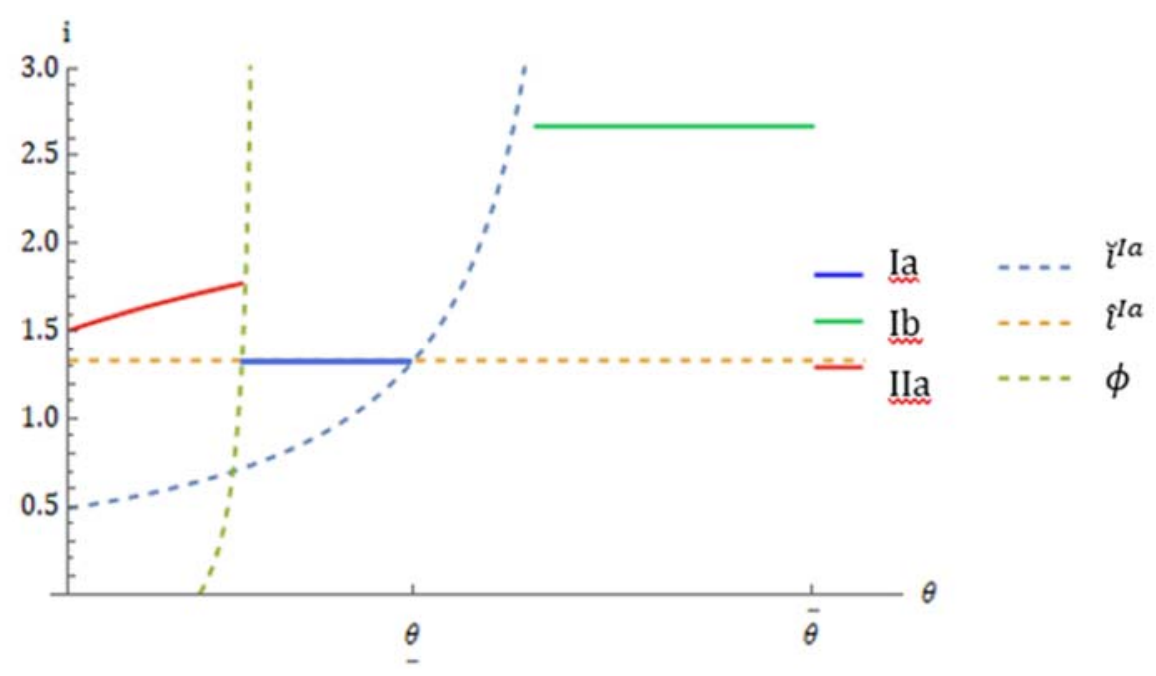

Lemma 4.) For $\underline{\theta}<\theta \leq \bar{\theta}$, the only equilibria are Type Ib and have $i=\hat{\imath}^{l b}$. They are depicted by the green line. Observe that for the moderate value of $\beta$ depicted here for values of $\theta$ greater than but close to $\underline{\theta}$, there are no Type Ib equilibria, because the $\bar{\ell}^{*}$ consistent with these values of $\theta$ is so low that it would be binding in the high productivity state.

In short, equilibria with positive debt holdings exist only when the interest rate is set at precisely the right level. Diagram 5 depicts welfare in these different equilibria.

Diagram 5- Welfare in Equilibrium: With Bill Holdings

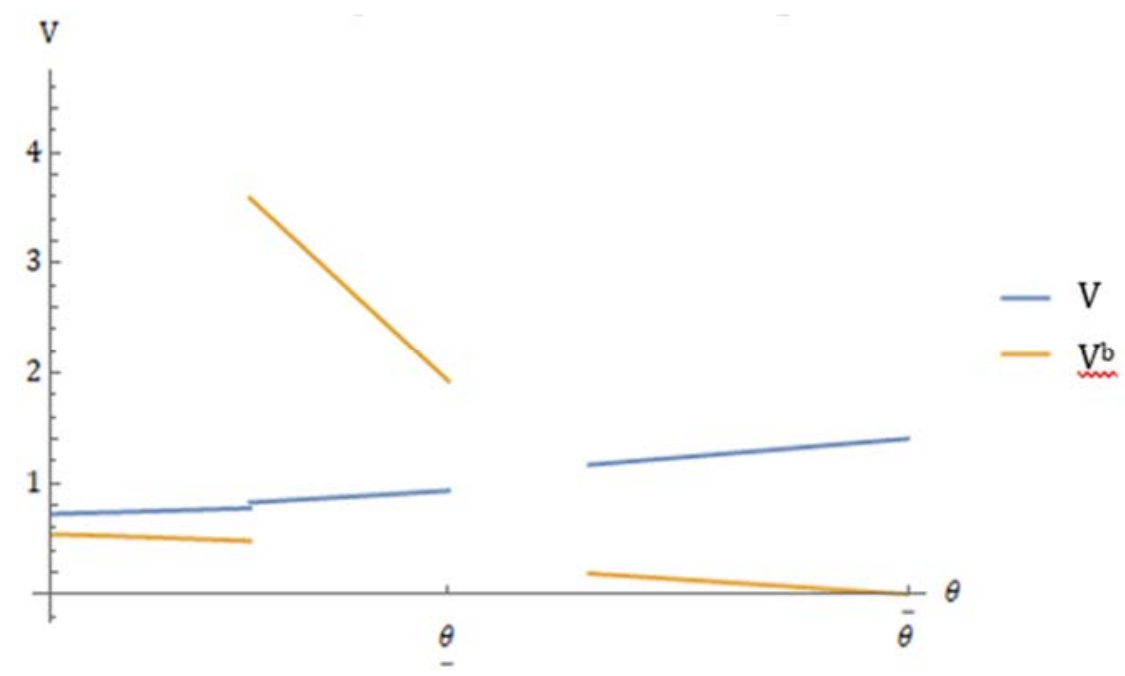


Diagram 5 shows that the steady state welfare of non-banks is increasing in the level of bill holdings, but only incrementally. The increase in welfare is generated by the fact that bill holdings allow borrowers to consume the same amount while borrowing less and therefore reduce interest payments and the cost incurred to make those payments. On the other hand, the fact that the Euler equation holds with equality across the Type Ia and the Type Ib equilibria indicates that the cost of moving to a higher welfare steady state is offset by the cost of producing enough to get there.

Another way to explain this point is to consider the case where $\beta$ is sufficiently high that when $\theta=0$, the only equilibria are Type Ia equilibria. In this case when $i=\hat{\imath}^{I a}$, there will be equilibria for $0 \leq \theta \leq \min [\underline{\theta}, \hat{\theta}]$, and as in the diagram above, any steady state at $\theta=\underline{\theta}$ will have higher non-bank welfare than the steady state at $\theta=0$. The implication of the Euler equation is, however, that any agent in the $\theta=0$ steady state has no desire to move to the "higher welfare" steady state - because the costs of getting there precisely offset the value of the move. That is, despite the fact that Diagram 5 indicates that the highest welfare steady state is at $\theta=\bar{\theta}$, this is only true if the agents start with $\theta=\bar{\theta}$, not if they have to get there by their own means. In short, despite the desirability of a high level of bill holdings that is implied by Diagram 5, in a world where agents are born without bill holdings this desirability does not exist.

Finally, observe that shifts from one equilibrium to the next have a very different effect on bankers than on non-bankers. Bankers generally lose when bill holdings increase as they receive less in interest payments. However, when $\theta$ rises high enough to permit a transition from a Type IIa, liquidity constrained, equilibrium to a Type Ia, unconstrained equilibrium, the equilibrium interest rate falls dramatically but is more than offset by an increase in consumption and thus in interest paid to banks. As a result, it is the bankers who capture most of the welfare gains due to the transition - and they would have an incentive to set interest rates so as to facilitate this transition.

The bottom line: This paper models banks as facilitating a means of exchange that is in fact a naked short of the unit of account. It demonstrates the welfare benefits of such a monetary system and the incentive compatibility of the naked short contract structure for both banks and non-banks. By comparing the welfare of the different types of equilibria in this section, we find that there is a strong welfare-based impetus for the banks and non-banks in an economy to develop the institutions that will support a monetary system that is anchored to a real consumption good, but where market participants, instead of storing the good, use credit-claims on the consumption good in order to transact. 


\section{SISSOKO The Nature of Money}

\section{How do we choose among equilibria when $\theta=0$ ?}

Since empirical studies typically conclude that annual discount rates are very high, usually above 0.95 , there is reason to believe that the "good" Type Ia equilibria will be incentive compatible for non-banks. The challenge in supporting Type Ia equilibria is the structure of the banking system. Lemma 2 states that a competitive banking sector will drive interest rates so low that a Type Ia equilibrium cannot be supported. In this section we consider policies that will make it possible to achieve a Type Ia equilibrium outcome in the environment of endogenous enforcement.

\subsection{Usury Laws}

One solution is to treat banking as a natural monopoly (or oligopoly), taking a permissive approach to an anti-competitive structure in the industry, while at the same time capping the price at which bank services are offered. Usury laws can be viewed as part of such an approach.

This paper studies the use of convertible currencies. One of the most important historical examples of a convertible currency is Britain's gold standard which had its origins in the British monetary experiments of the late 1690s (Horsefield 1960) and was the foundation upon which the classical Gold Standard that anchored world trade in the late $19^{\text {th }}$ century was built. Through the developmental stages of this British institution and of the British banking system that grew up with it, usury laws capped interest rates at $5 \%$ and as a practical matter through the $18^{\text {th }}$ century this was the rate charged by banks on bills (Pressnell 1956: 89). The late $18^{\text {th }}$ century monetary system as described by Thornton (1802) is the basis for the model of money in this paper. Because $18^{\text {th }}$ century British tradesmen typically had bills outstanding, held no gold, and preferred to hold as assets interest bearing bills of other tradesmen, they were effectively in equilibria with $\theta=0$, where no matured (non-interest-bearing) bills are carried over time.

Given the modern empirical evidence regarding discount factors, a 5\% usury rate appears to be a very reasonable policy: as diagram 2 indicates a $5 \%$ interest rate will be consistent with Type Ia equilibrium as long as the discount factor is relatively high (over 0.93 in the diagram) - which is consistent with the empirical evidence. For an economy that is in a Type Ia $\theta=0$ equilibrium, a $5 \%$ usury rate will function as a constraint on the interest rate charged by a notso-competitive banking sector, and will serve only to force this sector to share more of the surplus with the non-banks than would have been the case otherwise. In short, a usury rate in this model serves, as advertised, to protect the interests of the public at the expense of the financiers.

Of course, the $5 \%$ usury rate is found to be reasonable policy here, because it is not a longterm lending rate. This is instead the rate paid on payments system debt that is to be repaid over 
the very short-term and that is risk-free due to the careful calibration of borrowing constraints to ensure that it is incentive compatible.

The modern credit card system is testimony to the risk-free nature of payment system debt: most people have access to zero-interest payments system debt using their credit cards as long as the debt is repaid within 3 to 6 weeks after it is incurred - and they do not have an established history of failure to pay. (What makes the nature of the credit card system confusing is that it is combined with a system of high-interest rate long-term debt.) This model and the extraordinary success of historical financial systems that operated under a tight usury constraint indicate that imposing a usury rate on credit cards of 5\%-9\% might be an effective way of transferring value from the banks to consumers.

\subsection{Central bank lending rates}

Usury laws in Britain did not survive long into the $19^{\text {th }}$ century. They were replaced by an active central bank lending policy that is the prototype for modern central bank policy. The practice of the central bank setting interest rates can also be explained by this model.

When banks compete too aggressively they may drive the interest rate down so low that providing bank services is no longer incentive compatible for the bankers. When this takes place, the banks will issue too many liabilities, fail to honor them, and destabilize the monetary system. One solution to this problem is to promote competition in the banking sector, but at the same time set a floor below which the competitive interest rate may not fall.

In the model, if policymakers set the interest rate floor at $\breve{l}^{I a}$, then Bertrand competition in the banking sector will drive the interest rate to that level, a Type Ia equilibrium will be supported, and the policy will favor the interests of non-banks by ensuring that they pay the lowest possible equilibrium rate. Such a policy would imitate the current practice of the Federal Reserve in paying interest on reserves or the past practice of the Federal Reserve when it managed reserves to ensure that banks could lend at the Federal Funds Rate. In both cases, the fact that central bank policy ensures that banks can lend safely at a certain rate will have the effect of discouraging banks from reducing the rates they charge other borrowers below this level.

In short, this model provides a clear explanation for why central bank policy takes the form that it does. Central banks set the short-term interest rate to ensure that competition in the banking sector does not drive rates so low that the practice of banking will no longer be incentive compatible and that the banking system will be destabilized by banks that issue liabilities that cannot be honored. 


\section{SISSOKO The Nature of Money}

\section{Conclusion}

This paper models the role paid by banks in the payments system. Banks impose borrowing terms on non-banks that are consistent with incentive compatibility, including excluding them from the payments system if they default. By structuring payments system debt in this way banks are able to certify that non-bank debt is safe.

Payments system debt is by its nature short-term. To capture the short-term nature of this debt in the model, it is both incurred and paid off within a single period. A natural implication of the short-term nature of the debt is then that interest paid on payments system debt does not compensate for discounting over time, but instead serves to ensure that payments system debt is incentive compatible both for the banks and for the non-banks.

This model shows how banks can be the fulcra that institutionalize and organize the naked shorting of the unit of account. ${ }^{10}$ By doing so a "phantom" supply of the unit of account is created that exists only so long as the short-term payments system debt is outstanding.

By basing the monetary system on the principle of the naked short and imposing a convertible currency structure on our environment, we demonstrate that this function of banks is efficiency enhancing: the Euler equation makes it clear that nobody wants to carry over time a currency that is convertible at a fixed rate into real goods, and thus that it is efficiency enhancing for people living in a gold standard world to transact using credit instruments - as in fact was historically the case.

Indeed, we demonstrate that the first-best can be achieved by such a bank-based monetary system in a convertible currency environment with enforceable debt. Thus, this represents an alternative to fiat money and the Friedman Rule as a means of optimally addressing transactions frictions in an economy.

The paper focuses mostly, however, on the nature of the second-best equilibria that are incentive feasible when debt is not based on exogenous enforcement. In this case, non-bank borrowers face an endogenous borrowing limit. When discount rates are high, the borrowing limit does not bind, and it is the need to compensate the banks sufficiently that they are not incentivized to take advantage of their ability to issue naked shorts that bounds the allocation away from the first best.

A full analysis of the relationship between these second-best equilibria and fiat money is left to future work. We note here, however, first, that the fact that productivity is stochastic in

\footnotetext{
${ }^{10}$ The model also illustrates the cartalist principle that accepted bills circulate as money, because they are backed by debt. That is, lenders who receive accepted bills in payment do so because they know that the structure of the monetary system ensures that the producers in the next sub-period will need to pay back their bank loan and therefore will accept in payment the bill, because it can be used to settle their outstanding debt.
} 
our environment is likely to mean that a simple Friedman Rule will have limited effectiveness, and, second, that because bank money allows for both short and long positions in the unit of account, whereas fiat money allows for only long positions in the unit of account, it is likely that as long as discount rates are not too low bank money will expand the set of implementable allocations relative to fiat money and make it possible for higher welfare outcomes to be achieved.

This formal model of bank money as a naked short of the unit of account can also be adapted to the study of central bank digital currencies. If central bank digital currency is modeled as long only accounts held by non-banks at the central bank that can be spent down to but not below zero, then digital currency would be similar to fiat money. As a result, the likely result of a comparison between central bank digital money and bank money in this environment is that, as long as discount rates are not too low, a shift from bank money to central bank digital money would have adverse effects on the set of allocations, and the welfare, that is attainable in equilibrium. Thus, in future work we will use this environment to provide a theoretic foundation for the commonly voiced critique of central bank digital currencies that their adoption would have adverse effects by reducing the availability of bank loans and destabilizing the banking system (Broadbent 2016, Lowe 2017, Carney 2018).

\section{References}

Bayoumi, T. and Eichengreen, B. (1995). The Stability of the Gold Standard and the Evolution of the International Monetary System, IMF Working Paper WP/95/89. https://papers.ssrn.com/sol3/papers.cfm?abstract_id $=883236$

Berentsen, A., Camera, G., and Waller, C. (2007). Money, Credit, and Banking, 135 J Econ. Theory 171. http://qed.econ.queensu.ca/pub/students/phds/liuqian/MRG/ Fall_2007/ Berentsen Camera Waller2007.pdf

Broadbent, B. Central Banks and Digital Currencies, speech, March 2, 2016. https://www.bis.org/review/r160303e.pdf

Carney, M. The Future of Money, speech, March 2, 2018. https://www.bankofengland.co.uk//media/boe/files/speech/2018/the-future-of-money-speech-by-mark-carney.pdf

Cavalcanti, R. and Wallace, N. (1999a). A Model of Private Banknote Issue, 2 Rev. Econ. Dynamics 104 https://doi.org/10.1006/redy.1998.0044

Cavalcanti, R. and Wallace, N. (1999b). Inside and Outside Money as Alternative Media of Exchange, $31 \mathrm{~J}$. Money, Credit, \& Banking 443.

Demsetz, R.S., Saidenberg, M.R., and Strahan, P.E. (1996). Banks with Something to Lose: The Disciplinary Role of Franchise Value, FRBNY Econ. Pol. Rev. 1. 
Dunbar, C. (1909). Chapters on Banking.

Goodhart, C. (1988). The Evolution of Central Banks.

Lowe, P. An eAUD?, speech, December 13 2017. https://www.rba.gov.au/ speeches/2017/pdf/sp-gov-2017-12-13.pdf

Martin, A. and Shreft, S. (2005). Currency Competition: A Partial Vindication of Hayek. Federal Reserve Bank of Kansas City Research Working Paper No. RWP 03-04. https://pdfs.semanticscholar.org/4ccd/9b12afeaec6af2dc677555ccfeb6c22ac967.pdf

Gu, Mattesini, Monnet, and Wright. (2013). Banking a New Monetarist Approach, 80 Rev. Econ. Stud. 636. https://dx.doi.org/10.1093/restud/rds037

$\mathrm{Gu}$, Mattesini, and Wright, (2014). Money and Credit Redux. https://doi.org/ $\underline{10.3982 / \text { ECTA } 12798}$

Hawtrey, R. (2019) Currency and Credit.

Horsefield, J.K. (1960). British Monetary Experiments 1650-1710, Harvard U Press.

Kui Huang, A. (2017). On the Number and Size of Banks: Efficiency and Equilibrium, paper presented at Summer workshop on Money, Banking, Payment and Finance, Ottawa.

Kocherlakota, N. (1998). Money is Memory. https://doi.org/10.1006/jeth.1997.2357

Lagos, R. and Wright, R. (2005). A Unified Framework for Monetary Theory and Policy Analysis, 113 J. Pol. Econ. 463. https://www.jstor.org/stable/10.1086/ 429804?seq=1\#page_scan tab_contents

Monnet, C. and Sanches, D. (2015). Private Money and Banking Regulation, FRB Philadelphia Working Paper 15-19. https://www.philadelphiafed.org/-/media/research-anddata/publications/working-papers/2015/wp15-19.pdf

Nosal, E. and Rocheteau, G. (2011). Money, Payments, and Liquidity.

Pressnell, L.S. (1956). Country Banking in the Industrial Revolution.

Roberts, R. (1995). The Bank of England and the City in Richard Roberts \& David Kynaston ed. The Bank of England: Money, Power, and Influence 1694 - 1994.

Sanches, D. (2015). On the Inherent Instability of Private Money, FRB Philadelphia Working Paper 15-18. https://www.philadelphiafed.org/-/media/research-and-data/publications/ working-papers/2015/wp15-18.pdf?la=en

Sheppard, D. (1971). The Growth and Role of U.K. Financial Institutions 1880 - 1962.

Sissoko, C. (2016). How to Stabilize the Banking System: Lessons from the Pre-1914 London Money Market. Financial History Review 23, pp. $1-20$. https://doi.org/ $\underline{10.1017 / \mathrm{S} 0968565016000020}$

Thornton, H. (1802). An Enquiry into the Nature and Effects of the Paper Credit of Great Britain. 
Van Dillen, J.G. (1964). "The Bank of Amsterdam," in J. G. van Dillen ed. History of the

Principal Public Banks, reprint of 1934 edition, Frank Cass and Co., London.

Wicksell, K. Interest and Prices (R.F. Kahn transl., 1898).

Willis, H. P. (1916). American Banking

\section{Appendix 1: Derivation of Value Functions}

It is convenient for purposes of exposition to substitute out the equilibrium price level when defining expressions for the optimal consumption of $\operatorname{good} x, x^{*}(d, \bar{\ell}, A)$, the optimal supply of $\operatorname{good} x, q^{*}(d, \bar{\ell}, A)$, and the resulting income received from the sale of $\operatorname{good} x, p q^{*}(d, \bar{\ell}, A)$.

For optimal consumption, we find:

$$
x^{*}(d, \bar{\ell}, A)=\left\{\begin{array}{lr}
\chi(0) A^{\frac{1}{2-\alpha}} & \text { if } \pi(0) A^{\frac{\alpha}{2-\alpha}}<d \\
n . a . & \text { if } \pi(i) A^{\frac{\alpha}{2-\alpha}}<d<\pi(0) A^{\frac{\alpha}{2-\alpha}} \\
\chi(i) A^{\frac{1}{2-\alpha}} & \text { if } d \leq \pi(i) A^{\frac{\alpha}{2-\alpha}<\bar{\ell}+d} \\
{\left[\frac{n A(\bar{\ell}+d)}{(1-n)}\right]^{\frac{1}{2}}} & \text { otherwise }
\end{array}\right.
$$

where

$$
\chi(i) \equiv\left[\frac{\alpha n}{(1+i)(1-n)}\right]^{\frac{1}{2-\alpha}}
$$

The optimal supply of the FM good is given by:

$$
q^{*}(A, d, \bar{\ell})=\left\{\begin{array}{lr}
\zeta(0) A^{\frac{1}{2-\alpha}} & \text { if } \pi(0) A^{\frac{\alpha}{2-\alpha}<d} \\
n . a . & \text { if } \pi(i) A^{\frac{\alpha}{2-\alpha}<d<\pi(0) A^{\frac{\alpha}{2-\alpha}}} \\
\zeta(i) A^{\frac{1}{2-\alpha}} & \text { if } d \leq \pi(i) A^{\frac{\alpha}{2-\alpha}}<\bar{\ell}+d \\
{\left[\frac{A(1-n)(\bar{\ell}+d)}{n}\right]^{\frac{1}{2}}} & \text { otherwise }
\end{array}\right.
$$

where

$$
\zeta(i) \equiv\left[\frac{\alpha}{1+i}\right]^{\frac{1}{2-\alpha}}\left[\frac{(1-n)}{n}\right]^{\frac{1-\alpha}{2-\alpha}}
$$




\section{SISSOKO The Nature of Money}

And the resulting income received from the sale of the FM good is:

$$
p q^{*}(A, d, \bar{\ell})=\left\{\begin{array}{cr}
v(0) A^{\frac{\alpha}{2-\alpha}} & \text { if } \pi(0) A^{\frac{\alpha}{2-\alpha}}<d \\
n . a . & \text { if } \pi(i) A^{\frac{\alpha}{2-\alpha}}<d<\pi(0) A^{\frac{\alpha}{2-\alpha}} \\
v(i) A^{\frac{\alpha}{2-\alpha}} & \text { if } d \leq \pi(i) A^{\frac{\alpha}{2-\alpha}}<\bar{\ell}+d \\
\frac{(1-n)(\bar{\ell}+d)}{n} & \text { otherwise }
\end{array}\right.
$$

where

$$
v(i) \equiv\left[\frac{\alpha}{1+i}\right]^{\frac{2}{2-\alpha}}\left[\frac{(1-n)}{n}\right]^{\frac{2-2 \alpha}{2-\alpha}}
$$

Then the value function for Type Ia: Always borrow, $\mathrm{d} \leq \pi(i) \underline{A}^{\frac{\alpha}{2-\alpha}}$, is:

$$
\begin{aligned}
V^{1 a}(d)=(1- & \sigma)\left\{(1-n)\left[\chi(i)^{\alpha} \underline{A}^{\frac{\alpha}{2-\alpha}}+W^{l p}\left(\pi(i) \underline{A}^{\frac{\alpha}{2-\alpha}}-d, 0\right)\right]\right. \\
+ & \left.n\left[-\frac{\zeta(i)^{2}}{2} \underline{A}^{\frac{\alpha}{2-\alpha}}+W^{e p}\left(d+v(i) \underline{A}^{\frac{\alpha}{2-\alpha}}\right)\right]\right\} \\
+ & \sigma(1-n)\left[\chi(i)^{\alpha} \bar{A}^{\frac{\alpha}{2-\alpha}}+W^{l p}\left(\pi(i) \bar{A}^{\frac{\alpha}{2-\alpha}}-d, 0\right)\right] \\
+ & \left.n\left[-\frac{\zeta(i)^{2}}{2} \bar{A}^{\frac{\alpha}{2-\alpha}}+W^{e p}\left(d+v(i) \bar{A}^{\frac{\alpha}{2-\alpha}}\right)\right]\right\}
\end{aligned}
$$

And we can rewrite

$$
\begin{array}{r}
(1-n)\left[\chi(i)^{\alpha} A^{\frac{\alpha}{2-\alpha}}+W^{l p}\left(\pi(i) A^{\frac{\alpha}{2-\alpha}}-d, 0\right)\right]+n\left[-\frac{\zeta(i)^{2}}{2} A^{\frac{\alpha}{2-\alpha}}+W^{e p}(d+\right. \\
\left.\left.v(i) A^{\frac{\alpha}{2-\alpha}}\right)\right]
\end{array}
$$


Review of Economic Analysis 13 (2021) 1-43

$$
\begin{aligned}
& =(1-n)\left[\left[\frac{\alpha n}{(1+i)(1-n)}\right]^{\frac{\alpha}{2-\alpha}} A^{\frac{\alpha}{2-\alpha}}-(1+i)\left(\left[\frac{\alpha}{1+i}\right]^{\frac{2}{2-\alpha}}\left[\frac{(1-n)}{n}\right]^{\frac{-\alpha}{2-\alpha}} A^{\frac{\alpha}{2-\alpha}}-d\right)\right. \\
& \left.+W^{l p}(0,0)\right] \\
& +n\left[-\left[\frac{\alpha}{1+i}\right]^{\frac{2}{2-\alpha}}\left[\frac{(1-n)}{n}\right]^{\frac{2-2 \alpha}{2-\alpha}} \frac{A^{\frac{\alpha}{2-\alpha}}}{2}+d\right. \\
& \left.+\left[\frac{\alpha}{1+i}\right]^{\frac{2}{2-\alpha}}\left[\frac{(1-n)}{n}\right]^{\frac{2-2 \alpha}{2-\alpha}} A^{\frac{\alpha}{2-\alpha}}+W^{e p}(0)\right] \\
& =(1-n) A^{\frac{\alpha}{2-\alpha}}\left[\frac{(1-n)}{n}\right]^{\frac{-\alpha}{2-\alpha}}\left[\left[\frac{\alpha}{(1+i)}\right]^{\frac{\alpha}{2-\alpha}}-\left([\alpha]^{\frac{2}{2-\alpha}}(1+i)^{\frac{-\alpha}{2-\alpha}}\right)\right] \\
& +\frac{n A^{\frac{\alpha}{2-\alpha}}}{2}\left[\frac{(1-n)}{n}\right]^{\frac{2-2 \alpha}{2-\alpha}}\left[\frac{\alpha}{1+i}\right]^{\frac{2}{2-\alpha}}+d[(1-n)(1+i)+n] \\
& +n W^{e p}(0)+(1-n) W^{l p}(0,0) \\
& =(n A)^{\frac{\alpha}{2-\alpha}}(1-n)^{\frac{2-2 \alpha}{2-\alpha}}\left\{\left[\frac{\alpha}{(1+i)}\right]^{\frac{\alpha}{2-\alpha}}-\left([\alpha]^{\frac{2}{2-\alpha}}(1+i)^{\frac{-\alpha}{2-\alpha}}\right)+\frac{1}{2}\left[\frac{\alpha}{1+i}\right]^{\frac{2}{2-\alpha}}\right\} \\
& +d[(1-n)(1+i)+n]+n W^{e p}(0)+(1-n) W^{l p}(0,0) \\
& =\left(\frac{n \alpha A}{1+i}\right)^{\frac{\alpha}{2-\alpha}}(1-n)^{\frac{2-2 \alpha}{2-\alpha}}\left[1-\alpha+\frac{\alpha}{2(1+i)}\right]+d[(1-n)(1+i)+n]+n W^{e p}(0) \\
& +(1-n) W^{l p}(0,0)
\end{aligned}
$$

Thus we can conclude that Type Ia gives us the following value function:

$$
\begin{array}{r}
V^{1 a}(d)=\left(\frac{n \alpha}{1+i}\right)^{\frac{\alpha}{2-\alpha}}(1-n)^{\frac{2-2 \alpha}{2-\alpha}}\left[1-\alpha+\frac{\alpha}{2(1+i)}\right]\left[(1-\sigma)+\sigma \bar{A}^{\frac{\alpha}{2-\alpha}}\right] \\
+d[(1-n)(1+i)+n]+n W^{e p}(0)+(1-n) W^{l p}(0,0)
\end{array}
$$

Type Ib: Splitting, $d \in\left[\pi(0) \underline{A}^{\frac{\alpha}{2-\alpha}}, \pi(i) \bar{A}^{\frac{\alpha}{2-\alpha}}\right]$ 


$$
\begin{aligned}
V^{I b}(d)=(1- & \sigma)\left\{(1-n)\left[\chi(0)^{\alpha}+W^{l p}(0, d-\pi(0))\right]\right. \\
+ & \left.n\left[-\frac{\zeta(0)^{2}}{2}+W^{e p}(d+v(0))\right]\right\} \\
+ & \sigma\left\{(1-n)\left[\chi(i)^{\alpha} \bar{A}^{\frac{\alpha}{2-\alpha}}+W^{l p}\left(\pi(i) \bar{A}^{\frac{\alpha}{2-\alpha}}-d, 0\right)\right]\right. \\
+ & \left.n\left[-\frac{\zeta(i)^{2}}{2} \bar{A}^{\frac{\alpha}{2-\alpha}}+W^{e p}\left(d+v(i) \bar{A}^{\frac{\alpha}{2-\alpha}}\right)\right]\right\}
\end{aligned}
$$

Following the same method as for Type Ia, we find:

$$
\begin{aligned}
& V^{I b}(d)=(1-n)^{\frac{2-2 \alpha}{2-\alpha}}(n \alpha)^{\frac{\alpha}{2-\alpha}}\left[(1-\sigma)\left(1-\frac{\alpha}{2}\right)+\sigma\left[1-\alpha+\frac{\alpha}{2(1+i)}\right]\left(\frac{\bar{A}}{1+i}\right)^{\frac{\alpha}{2-\alpha}}\right] \\
& +d[\sigma(1-n)(1+i)+(1-\sigma(1-n))]+n W^{e p}(0)+(1 \\
& -n) W^{l p}(0,0)
\end{aligned}
$$

Type Ic: Never borrow, $\mathrm{d} \geq \pi(0) \bar{A}^{\frac{\alpha}{2-\alpha}}$

$$
\begin{aligned}
V^{I c}(d)=(1-\sigma) & \left\{(1-n)\left[\chi(0)^{\alpha}+W^{l p}(0, d-\pi(0))\right]\right. \\
+ & \left.n\left[-\frac{\zeta(0)^{2}}{2}+W^{e p}(d+v(0))\right]\right\} \\
+ & \sigma\left\{(1-n)\left[\chi(0)^{\alpha} \bar{A}^{\frac{\alpha}{2-\alpha}}+W^{l p}\left(0, d-\pi(0) \bar{A}^{\frac{\alpha}{2-\alpha}}\right)\right]\right. \\
+ & \left.n\left[-\frac{\zeta(0)^{2}}{2} \bar{A}^{\frac{\alpha}{2-\alpha}}+W^{e p}\left(d+v(0) \bar{A}^{\frac{\alpha}{2-\alpha}}\right)\right]\right\}
\end{aligned}
$$

Following the same method as for Type Ia, we find:

$$
\begin{aligned}
& V^{I c}(d)=(1-\left.\frac{\alpha}{2}\right)(1-n)^{\frac{2-2 \alpha}{2-\alpha}}(n \alpha)^{\frac{\alpha}{2-\alpha}}\left[(1-\sigma)+\sigma \bar{A}^{\frac{\alpha}{2-\alpha}}\right]+d+n W^{e p}(0)+(1 \\
&-n) W^{l p}(0,0)
\end{aligned}
$$

Type IIa: Always borrow and $\bar{\ell}$ only binds for $\bar{A}, \pi(i) \leq \bar{\ell}+d<\pi(i) \bar{A}^{\frac{\alpha}{2-\alpha}}$ 
Review of Economic Analysis 13 (2021) 1-43

$$
\begin{aligned}
V^{I I a}(d)=(1-\sigma) & \left\{(1-n)\left[\chi(i)^{\alpha}+W^{l p}(\pi(i)-d, 0)\right]\right. \\
+ & \left.n\left[-\frac{\zeta(i)^{2}}{2}+W^{e p}(d+v(i))\right]\right\} \\
+ & \left\{(1-n)\left[\left[\frac{\left.n \bar{A}(\bar{\ell}+d)]^{\frac{\alpha}{2}}+W^{l p}(\bar{\ell}, 0)\right]}{(1-n)}\right]^{2}\right]\right. \\
+ & {\left.\left[-\frac{(1-n)(\bar{\ell}+d)}{2 n}+W^{e p}\left(d+\frac{(1-n)(\bar{\ell}+d)}{n}\right)\right]\right\} }
\end{aligned}
$$

After some algebra we get:

$$
\begin{aligned}
V^{I I a}(d)=(1- & \sigma)\left(\frac{n \alpha}{1+i}\right)^{\frac{\alpha}{2-\alpha}}(1-n)^{\frac{2-2 \alpha}{2-\alpha}}\left[1-\alpha+\frac{\alpha}{2(1+i)}\right] \\
& +(1-\sigma) d[(1-n)(1+i)+n]+\sigma(1-n)^{\frac{2-\alpha}{2}}[n \bar{A}(\bar{\ell}+d)]^{\frac{\alpha}{2}} \\
& +\sigma\left[n d-(1-n)(1+i) \bar{\ell}+\frac{(1-n)(\bar{\ell}+d)}{2}\right]+n W^{e p}(0)+(1 \\
& -n) W^{l p}(0,0)
\end{aligned}
$$

Type IIb: $d \geq \pi(i)$, borrow and $\bar{\ell}$ binds for $\bar{A}, \pi(i) \leq \bar{\ell}+d<\pi(i) \bar{A}^{\frac{\alpha}{2-\alpha}}$

$$
\begin{aligned}
& V^{I I b}(d)=(1-\sigma)\left\{(1-n)\left[\chi(0)^{\alpha}+W^{l p}(0, d-\pi(i))\right]\right. \\
& \left.+n\left[-\frac{\zeta(i)^{2}}{2}+W^{e p}(d+v(i))\right]\right\} \\
& +\sigma\left\{(1-n)\left[\left[\frac{n \bar{A}(\bar{\ell}+d)}{(1-n)}\right]^{\frac{\alpha}{2}}+W^{l p}(\bar{\ell}, 0)\right]\right. \\
& \left.+n\left[-\frac{(1-n)(\bar{\ell}+d)}{2 n}+W^{e p}\left(d+\frac{(1-n)(\bar{\ell}+d)}{n}\right)\right]\right\} \\
& V^{I I b}(d)=(1-\sigma)(\alpha n)^{\frac{\alpha}{2-\alpha}}(1-n)^{\frac{2-2 \alpha}{2-\alpha}}\left(1-\frac{\alpha}{2}\right)+\sigma(1-n)^{\frac{2-\alpha}{2}}[n \bar{A}(\bar{\ell}+d)]^{\frac{\alpha}{2}} \\
& -\sigma(1-n)\left[\frac{\bar{\ell}+d}{2}+i \bar{\ell}\right]+\beta V^{I I b}(d)
\end{aligned}
$$




\section{SISSOKO The Nature of Money}

Type III: Always borrow and $\bar{\ell}$ always binds, $\bar{\ell}+d<\pi(i) \underline{A}^{\frac{\alpha}{2-\alpha}}$

$$
\begin{aligned}
V^{I I I}(d)=(1- & \sigma)\left\{(1-n)\left[\left[\frac{n(\bar{\ell}+d)}{(1-n)}\right]^{\frac{\alpha}{2}}+W^{l p}(\bar{\ell}, 0)\right]\right. \\
+ & \left.n\left[-\frac{(1-n)(\bar{\ell}+d)}{2 n}+W^{e p}\left(d+\frac{(1-n)(\bar{\ell}+d)}{n}\right)\right]\right\} \\
& +\sigma\left\{(1-n)\left[\left[\frac{n \bar{A}(\bar{\ell}+d)}{(1-n)}\right]^{\frac{\alpha}{2}}+W^{l p}(\bar{\ell}, 0)\right]\right. \\
& \left.+n\left[-\frac{(1-n)(\bar{\ell}+d)}{2 n}+W^{e p}\left(d+\frac{(1-n)(\bar{\ell}+d)}{n}\right)\right]\right\}
\end{aligned}
$$

After some algebra we get:

$$
V^{I I I}(d)=\frac{1}{1-\beta}\left\{(1-n)^{\frac{2-\alpha}{2}}[n(\bar{\ell}+d)]^{\frac{\alpha}{2}}\left[(1-\sigma)+\sigma(\bar{A})^{\frac{\alpha}{2}}\right]-(1-n)\left(\frac{\bar{\ell}+d}{2}+i \bar{\ell}\right)\right\}
$$

